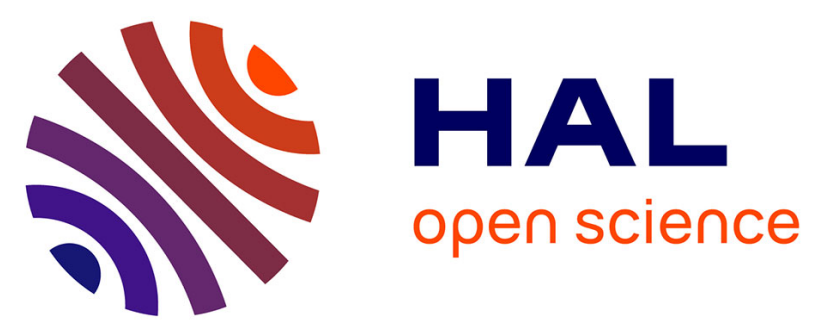

\title{
An IgG-induced neutrophil activation pathway contributes to human drug-induced anaphylaxis
}

Friederike Jönsson, Luc de Chaisemartin, Vanessa Granger, Aurélie

Gouel-Chéron, Caitlin Gillis, Qianqian Zhu, Fadia Dib, Pascale

Nicaise-Roland, Christelle Ganneau, Maria Hurtado-Nedelec, et al.

\section{To cite this version:}

Friederike Jönsson, Luc de Chaisemartin, Vanessa Granger, Aurélie Gouel-Chéron, Caitlin Gillis, et al.. An IgG-induced neutrophil activation pathway contributes to human drug-induced anaphylaxis. Science Translational Medicine, 2019, 11 (500), pp.eaat1479. 10.1126/scitranslmed.aat1479 . pasteur-02294649

\section{HAL Id: pasteur-02294649}

https://hal-pasteur.archives-ouvertes.fr/pasteur-02294649

Submitted on 23 Sep 2019

HAL is a multi-disciplinary open access archive for the deposit and dissemination of scientific research documents, whether they are published or not. The documents may come from teaching and research institutions in France or abroad, or from public or private research centers.
L'archive ouverte pluridisciplinaire HAL, est destinée au dépôt et à la diffusion de documents scientifiques de niveau recherche, publiés ou non, émanant des établissements d'enseignement et de recherche français ou étrangers, des laboratoires publics ou privés. 


\section{An IgG-induced neutrophil activation pathway during human drug-induced anaphylaxis}

Authors: Friederike Jönsson ${ }^{1,2, \dagger}$, Luc de Chaisemartin ${ }^{3,4, \dagger}$, Vanessa Granger ${ }^{3,4, \ddagger}$, Aurélie GouelChéron $^{1,2,5, \$}$, Caitlin M. Gillis ${ }^{1,2}$, Qianqian Zhu ${ }^{1,2,4}$, Fadia Dib ${ }^{6}$, Pascale Nicaise-Roland ${ }^{3}$, Christelle Ganneau $^{7,8}$, Maria Hurtado-Nedelec ${ }^{9}$, Catherine Paugam-Burtz ${ }^{10}$, Skander Necib ${ }^{10}$, Hawa KeitaMeyer $^{11}$, Matthieu Le Dorze ${ }^{12}$, Bernard Cholley ${ }^{13}$, Olivier Langeron ${ }^{14}$, Laurent Jacob ${ }^{15}$, Benoit Plaud $^{15}$, Marc Fischler ${ }^{16}$, Caroline Sauvan ${ }^{17}$, Marie-Thérèse Guinnepain ${ }^{18}$, Philippe Montravers $^{5,19}$, Michel Aubier ${ }^{17,19}$, Sylvie Bay ${ }^{7,8}$, Catherine Neukirch ${ }^{17,19}$, NASA study group, Florence Tubach ${ }^{20, \S}$, Dan Longrois ${ }^{3,5, \S}$, Sylvie Chollet-Martin ${ }^{3,4, \S,{ }^{*}}$ and Pierre Bruhns ${ }^{1,2, \S, *}$

\section{Affiliations:}

${ }^{1}$ Institut Pasteur, Department of Immunology, Unit of Antibodies in Therapy and Pathology, Paris, France.

${ }^{2}$ INSERM, U1222, Paris, France.

${ }^{3}$ Département d'Immunologie et d'Hématologie, UF Auto-immunité et Hypersensibilités, HUPNVS, Hôpital Bichat, Paris, France.

${ }^{4}$ Inflammation Chimiokines et Immunopathologie, INSERM UMRS996, Faculté de Pharmacie, Université Paris-Sud, Université Paris-Saclay, Châtenay-Malabry, France.

${ }^{5}$ APHP, Hôpital Bichat, Département d'Anesthésie-Réanimation, HUPNVS, Paris, France.

${ }^{6}$ APHP, Hôpital Bichat, Department of Epidemiology and Clinical Research, INSERM, Paris, France.

${ }^{7}$ Institut Pasteur, Département Biologie Structurale et Chimie, Unité de Chimie des Biomolécules, Paris, France.

${ }^{8}$ CNRS UMR 3523, Paris, France.

${ }^{9}$ Département d'Immunologie et d'Hématologie, UF Dysfonctionnements Immunitaires, HUPNVS, Hôpital Bichat, Paris, France.

${ }^{10}$ Département d'Anesthésie-Réanimation, Hôpital Beaujon, AP-HP, Clichy, France, and Université Paris Diderot, Paris, France.

${ }^{11}$ Service d'anesthésie, Hôpital Louis Mourier, AP-HP, Colombes, France and Université Paris Diderot, Sorbonne Paris Cité, EA Recherche Clinique coordonnée ville-hôpital, Méthodologies et Société (REMES), Paris, France.

${ }^{12}$ Département d'Anesthésie-Réanimation, Hôpital Lariboisière, AP-HP, Paris, France. 
${ }^{13}$ Service d'Anesthésie-Réanimation, Hôpital Européen Georges Pompidou, AP-HP, Paris, France and Université Paris Descartes, Sorbonne Paris Cité, Paris, France.

${ }^{14}$ Department of Anesthesia and Critical Care, Hôpital Pitié Salpêtrière, AP-HP, Sorbonne Université, Paris, France and Infection and Epidemiology Department, Institut Pasteur Human Histopathology and Animal Models Unit, Paris, France

${ }^{15}$ Département d'Anesthésie-Réanimation, Hôpital Saint Louis, AP-HP, Paris, France.

${ }^{16}$ Service d'Anesthésie, Hôpital Foch, Sureses, France.

${ }^{17}$ APHP, Hôpital Bichat, Service de Pneumologie A, HUPNVS, Paris, France.

${ }^{18}$ Hôpital Foch, Service de médecine interne, Suresnes, France.

${ }^{19}$ INSERM 1152, DHU FIRE, Labex Inflamex, Université Paris Diderot Paris 7, Paris, France.

${ }^{20}$ Sorbonne Université, AP-HP, Hôpital Pitié-Salpêtrière, Département Biostatistique Santé Publique et Information Médicale, Unité de Recherche Clinique PSL-CFX, Centre de Pharmacoépidémiologie (Cephepi), INSERM, UMR 1123, CIC-1421, Paris.

$\dagger, \star$ : Equal contribution.

$\S:$ Co-senior authorship.

*To whom correspondence should be addressed: Pierre Bruhns, Unit of Antibodies in Therapy and Pathology, Department of Immunology, Institut Pasteur, 25 rue du Docteur Roux, 75015 Paris, France. Phone: +33145688629. E-mail: bruhns@pasteur.fr; Sylvie Chollet-Martin, UF Auto-immunité et Hypersensibilités, Hôpital Bichat, HUPNVS, APHP, Paris, France, 46 rue Henri Huchard, 75018 Paris, France. Phone : +33140256897. E-mail: sylvie.martin2@aphp.fr

One Sentence Summary: Co-existence of specific IgE and IgG antibodies aggravates NMBAinduced anaphylaxis in humans

\begin{abstract}
:
Anaphylaxis is a systemic acute hypersensitivity reaction that is considered to depend on allergenspecific IgE antibodies, and histamine release by mast cells and basophils. Nevertheless, specific IgG have been proposed to contribute when the allergen is a large molecule circulating at a high dose, e.g. following therapeutic antibodies or dextran infusions. Data from animal models support a (predominant) role for IgG during anaphylaxis to large protein antigens; and a pathway involving platelet-activating factor (PAF) release by monocyte/macrophages and neutrophils activated via their IgG receptors. We hypothesized that such a pathway may also apply to small drugs and could be responsible for non-IgE mediated anaphylaxis and contribute to anaphylaxis severity in humans.
\end{abstract}


We prospectively conducted a multicentric study of 86 patients with suspected anaphylaxis to neuromuscular-blocking agents (NMBA) during general anesthesia and 86 matched controls. We found that concentrations of anti-NMBA IgG and markers of IgG receptor activation, PAF release and neutrophil activation correlated with anaphylaxis severity. Neutrophils underwent degranulation and netosis early after anaphylaxis onset, and plasma-purified anti-NMBA IgG triggered neutrophil activation ex vivo in the presence of NMBA. Importantly, neutrophil activation could also be observed in patients lacking evidence of classical IgE-dependent anaphylaxis. This study supports the existence of an IgG-neutrophil-PAF pathway in human NMBA-induced anaphylaxis, which may aggravate anaphylaxis in combination with the IgEpathway or underlie anaphylaxis in the absence of specific IgE. These results reconcile clinical and experimental data on the role of antibody classes in anaphylaxis, and should inform diagnostic approaches to NMBA-induced acute hypersensitivity reactions. 


\section{[Main Text: ]}

\section{Introduction}

Anaphylaxis is an immune-mediated systemic acute hypersensitivity reaction (AHR) occurring rapidly upon contact with an allergen in sensitized individuals. Clinical signs include bronchoconstriction, severe vasodilatation and hypovolemia that can lead to multi-organ dysfunction and death. The most prominent cause of anaphylaxis in adult is drugs, notably antibiotics and neuromuscular blocking agents (NMBA). Anaphylaxis is classically considered to rely on IgE antibodies against the allergen/antigen, and to involve massive histamine liberation by mast cells and basophils, following antigen-induced aggregation of $\operatorname{IgE}$ receptor (FceRI)-bound specific IgE antibodies (1). The clinical diagnosis of anaphylaxis to NMBA is based on this IgE paradigm. Surprisingly, to $10-20 \%$ of patients who experience an AHR consistent with an anaphylactic reaction do not present with any biological signs of IgE-dependent immune activation (positive skin test, presence of specific IgE, elevated histamine or tryptase concentrations) $(2,3)$, suggestive of other potential mechanisms. Among these, $\operatorname{IgG}$ antibodies have been proposed to trigger IgE-independent anaphylaxis induced by some protein antigens or large molecules (e.g. therapeutic antibodies, protamine, dextran) (3-9), but the underlying pathological mechanism remains however largely unknown. Furthermore, there is a lack of understanding of why for some patients the severity of the AHR varies widely, despite similar degrees of activation of the IgE pathway.

Supporting a paradigm of non IgE-dependent pathways of anaphylaxis, mouse studies have demonstrated that anaphylactic reactions may occur in the absence of $\operatorname{IgE}(10), \operatorname{IgE}$ receptors (11, 12) or mast cells $(12,13)$. Antibodies of the $\operatorname{IgG}$ class are often responsible for these non- $\operatorname{IgE}$ reactions, via the generation of IgG-antigen/allergen immune complexes (ICs). These complexes 
engage IgG receptors (Fc $\gamma \mathrm{R})$ on various myeloid cells (14-16), including monocytes/macrophages $(17,18)$ or neutrophils $(19)$, but also basophils $(20)$ or mast cells $(12)$, depending on the model of anaphylaxis used. FceRI or Fc $\gamma R$ engagement leads to internalization and downregulation of these receptors (21), which has been proposed as means to distinguish types of anaphylaxis, i.e. FceRI downregulation on mast cells and basophils as a marker of IgE-induced anaphylaxis (22) and Fc $\gamma \mathrm{R}$ downregulation on neutrophils and/or monocytes as a marker of IgG-induced anaphylaxis $(23,24)$. Our previous work showed that neutrophils play a dominant pathogenic role in mouse models of severe anaphylaxis (19); including models driven by human IgG and human IgG receptors (24, 25), suggesting that neutrophils could also contribute to anaphylaxis in humans. Neutrophils may even be sufficient to induce anaphylactic symptoms, as they can rapidly release a number of potent lipid and protein mediators upon activation, and can also extrude their genomic and mitochondrial DNA decorated by potent enzymes in the form of Neutrophil Extracellular Traps (NETs) - a process termed netosis (26). Neutrophils are major producers of platelet-activating factor (PAF) $(27,28)$ and release PAF in vitro upon Fc $\gamma \mathrm{R}$ triggering $(19,25)$, which also implicates these cells in anaphylaxis pathogenesis. Indeed, IgG-dependent experimental anaphylaxis in animal models has been repeatedly reported to rely on PAF as a mediator, alone or in combination with histamine $(15,19,20,24,29,30)$. Importantly, elevated PAF concentrations can be detected in the serum of human patients following anaphylaxis and correlate with reaction severity $(31,32)$.

To investigate the putative contribution of an "IgG antibody - neutrophil - PAF" pathway to human anaphylaxis to small drug molecules, we performed a first-in-kind prospective multicentric study on patients with suspected NMBA-induced AHR during anesthesia. We found that neutrophils were activated early after anaphylaxis onset and underwent degranulation as well as netosis. Anti-NMBA specific IgG concentrations, neutrophil activation markers, IgG receptor 
downregulation and PAF-acetylhydrolase (PAF-AH) activity were associated with anaphylaxis severity. Importantly, neutrophil activation was observed in patients for whom evidence of classical IgE-dependent anaphylaxis was lacking. Finally, plasma-purified anti-NMBA $\operatorname{IgG}$ antibodies triggered neutrophil activation and netosis ex vivo in the presence of NMBA. A pathogenic IgG-neutrophil-PAF pathway may thus underlie severe drug-induced anaphylactic events in humans. 


\section{[ Results : ]}

\section{Anti-NMBA specific IgE and IgG concentrations associate with anaphylaxis severity}

Due to the unpredictability and low-incidence of anaphylactic events to NMBA (1 out of 10,000 anesthesia procedures), we prospectively recruited a multicentric cohort of patients with acute hypersensitivity reactions to NMBA injection, along with matched controls (Tables 1-2; additional parameters of the cohort described in reference (33)). Reaction severity was retrospectively classified as mild (grade 1 and 2) or severe (grade 3 and 4) according to Ring and Messmer classification. Patients $(n=86)$ received suxamethonium $(n=39)$, atracurium $(n=35)$, rocuronium $(n=3)$ or a mixture of atracurium and suxamethonium (n=9) (Fig.1b-d; Table S1). Among those the frequency of severe (grade 3/4) AHR was $72 \%, 37 \%, 33 \%$ and $22 \%$, respectively, indicating that severe reactions can occur in response to any of the NMBA used.

All NMBA contain quaternary ammonium groups, which are considered the main antigenic epitope. Circulating anti-NMBA antibodies were quantified using the quaternary ammonium morphine compound (QAM; Fig.1a) as a surrogate molecule: thereby antibodies against this shared epitope were detected as serum anti-QAM IgE and anti-QAM IgG. As expected (34), anti-QAM IgE were elevated in patients with AHR compared to controls $(\mathrm{P}<0.0001)$, but were also higher in patients with reactions graded as severe versus mild $(\mathrm{P}<0.0001)$ (Fig. 1d; Table S1). Anti-QAM IgE are considered the most sensitive biomarker in NMBA-anaphylaxis (35), and were not detected in $98 \%$ of controls, yet surprisingly were also undetectable in $72 \%$ of patients with anaphylaxis. Conversely, circulating anti-QAM IgG were detected in all controls and patients, but nevertheless were found at significantly higher concentrations in patients with severe AHR 
compared to mild $(\mathrm{P}<0.0001)$, or to controls $(\mathrm{P}=0.007)$ (Fig.1e). Patients with very low $(<0.5 \mu \mathrm{g} / \mathrm{mL})$ anti-QAM IgG had undetectable anti-QAM IgE (Fig.1f). Detectable anti-QAM IgE concentrations correlated significantly with anti-QAM $\operatorname{IgG}(\mathrm{P}=0.0009$, Fig.1f, inset), indicating that whenever a patient had high anti-QAM IgE they also had high anti-QAM-specific IgG. Importantly, the reverse was not true, as several patients had anti-QAM specific IgG without detectable IgE. Irrespective of reaction severity, patients presenting with the highest anti-QAM IgE or IgG concentrations also tended to present with high anti-NMBA-specific IgE and IgG, detected via both clinically-validated and research-grade ImmunoCAP assays (Fig. S1). Thus, both anti-QAM IgE and IgG concentrations correlated with NMBA-induced anaphylaxis severity.

\section{IgG receptor downregulation on neutrophils is associated with anaphylaxis severity}

The presence of elevated concentrations of circulating anti-QAM IgE and $\operatorname{IgG}$ in patients with severe AHR suggests that upon intravenous injection, NMBA may immediately interact with anti-NMBA IgE-sensitized cells in circulation and that ICs of [anti-NMBA IgG - NMBA] may instantaneously form to engage Fc $\gamma$ Rs on myeloid cells. Our analyses revealed significantly lower FceRI expression on basophils, but not on eosinophils, from patients during severe AHR compared to their baseline expression measured during the follow-up visit (V2) or compared to controls (Fig.2a,b; $\mathrm{P}=0.02$ and $\mathrm{P}=0.01$, respectively). Among $\mathrm{IgG}$ receptors (Fig.2c-1), CD32A and CD16, but not CD64, demonstrated lower expression on neutrophils from severe AHR patients during AHR compared to controls (Fig.2e,k). Importantly, this reduction was also apparent compared to baseline expression measured during the follow-up visit (V2), indicating that these IgG receptors are not constitutively downregulated in these patients. Downregulation of CD32A and CD16 on neutrophils was significantly more pronounced in patients with severe versus mild reactions 
( $\mathrm{P}<0.0001$ and $\mathrm{P}=0.0004$, respectively). Monocytes from patients with severe AHR also demonstrated modest CD32A downregulation compared to controls, but no modulation of CD64, CD16 or of the inhibitory IgG receptor CD32B (Fig.2d,h,j,1). Basophils showed a tendency towards reduction of CD32B during severe AHR compared to baseline expression (V2), mild AHR patients or controls (Fig.2i). When we performed similar analyses after segregating patients according to the NMBA administered, we confirmed a downregulation of CD32A and CD16 on neutrophils and CD32A on monocytes during suxamethonium-induced $\mathrm{AHR}$, and of CD32A on neutrophils during atracurium-induced AHR (Fig. S2a-d). Of note, there were too few rocuroniuminduced severe AHR cases to permit statistical comparisons in this particular subgroup. Altogether, these data reveal downregulation of specific activating $\operatorname{IgG}$ receptors on neutrophils and monocytes in patients with severe AHR. These data are consistent with the hypothesis that Fc $\gamma \mathrm{R}$ are engaged by circulating IgG-ICs following NMBA injection in AHR patients. Further supporting this hypothesis, concentrations of complement components $\mathrm{C} 3$ and $\mathrm{C} 4$, and complement activity (50\% hemolytic activity, CH50) were significantly reduced during severe AHR compared to baseline (V2) $(\mathrm{P}<0.0001$, Fig. S3), suggesting activation of the classical complement pathway by IgG-ICs during severe NMBA-anaphylaxis.

\section{Neutrophils are activated during human anaphylaxis}

Downregulation of activating IgG receptors during AHR was predominant on neutrophils compared to other myeloid cells (Fig.2). We therefore investigated the activation status of neutrophils during AHR by measuring surface markers CD11b, CD18 and CD66b, circulating neutrophil elastase, DNA-myeloperoxidase complexes (DNA-MPO) as a measure of circulating NETs and PAF-acetylhydrolase (PAF-AH) activity, as an indirect measure of PAF concentrations. Expression of CD11b, CD18 and CD66b were all significantly increased on neutrophils from 
patients with severe AHR compared to controls $(\mathrm{P}=0.0003, \mathrm{P}=0.001$, and $\mathrm{P}=0.02$, respectively; Fig.3a-c). Neutrophil elastase was significantly increased in the plasma during severe AHR compared to controls, or to baseline (V2) concentrations ( $\mathrm{P}<0.0001$ for both, Fig.3d). DNA-MPO complexes detected in the serum, were also significantly increased in severe AHR compared to controls $(\mathrm{P}<0.0001)$ or patients with mild AHR $(\mathrm{P}<0.0001$, Fig.3e). PAF-AH activity was significantly lower in patients with severe AHR compared to controls or mild AHR ( $\mathrm{P}<0.0001$ and $\mathrm{P}=0.01$, respectively, Fig.3f), which is indicative of elevated plasma PAF concentrations. Interestingly, expression of both $\mathrm{CD} 11 \mathrm{~b}$ and $\mathrm{CD} 18$, and circulating concentrations of DNA-MPO complexes, were also significantly higher in patients with mild AHR compared to controls $(\mathrm{P}=0.004, \mathrm{P}=0.007$ and $\mathrm{P}=0.001)$ indicating that evidence of an $\mathrm{IgG}$ pathway of immune activation is not only associated with severe AHR (Fig.3a,b,e). Moreover, CD11b, CD18 and DNA-MPO remained elevated in severe AHR patients even 6-8 weeks after the reaction (V2, Fig.3a,b,e). Similar analyses after separating patients according to the NMBA used supports and sustained upregulation of CD11b and CD18 on neutrophils and NET release during and after suxamethonium-induced severe AHR (Fig. S2e,f). To ascertain that the link between neutrophil activation and anaphylaxis severity was not biased by treatments given during AHR (epinephrine, fluids, or other drugs), we incubated neutrophils from healthy donors with a wide range of concentrations of these compounds in vitro and assessed neutrophil activation, or capacity to be activated by standard stimuli. Epinephrine, ephedrine, atropine and resuscitation fluids had no effect on neutrophil activation. Only methylprednisolone at concentrations far above therapeutic range could induce a weak neutrophil activation as measured by NET release (Fig. S4). Of note, no correlation between corticosteroid administration (in 20/86 patients) and serum NET concentrations or AHR severity could be identified in the cohort. Altogether these data provide 
evidence of neutrophil activation in patients with intra-anesthetic AHR and demonstrate that the degree of neutrophil activation associates with AHR severity.

IgG-dependent neutrophil activation can occur concomitantly with, or independently of IgEmediated anaphylaxis

Patients experiencing severe AHR had higher anti-QAM IgE and decreased FceRI expression on basophils compared to controls (Fig.1-2), as well as elevated histamine and tryptase concentrations (Table S2). The same patients also had higher anti-QAM IgG concentration, decreased Fc $\gamma \mathrm{R}$ expression and greater evidence of neutrophil activation and degranulation (Fig.13) compared to controls. Patients with severe AHR thus presented markers typical of both IgEand IgG-dependent anaphylaxis. To assess if an IgG-dependent pathway could exist independently of the IgE-dependent pathway, we evaluated the presence of IgG-pathway markers relative to the likelihood of IgE-dependent activation. To this end, evidence for an IgE-dependent anaphylactic reaction was classified as "absent" (n=27, 31\%), "equivocal”" $(n=19,22 \%)$ or "strong" $(n=40,47 \%)$ for each patient based on clinical data, skin tests and biological tests used in standard care, by a consortium of experts blinded to the IgG status of the patients (33) (see Methods). Only the "strong" patient subgroup presented significantly reduced FceRI expression on basophils, compared to controls, "absent" or "equivocal" groups (Fig.4a, $\mathrm{P}=0.001, \mathrm{P}=0.003$ and $\mathrm{P}=0.01$, respectively). The "strong" patient group had higher anti-NMBA IgG (Fig.4b), lower CD32B expression on basophils (Fig.4c), lower CD32A expression on monocytes (Fig.4d), lower CD32A and CD16 expression on neutrophils (Fig.4e-f) and higher circulating elastase and DNA-MPO complexes concentrations (Fig.4g-h), compared to controls. This group also showed higher CD11b, CD18 and CD66b expression on neutrophils (Fig.4i-k) and lower PAF-AH activity 
(Fig.41). Furthermore, the "strong" patient group also had significantly higher anti-NMBA IgG, elastase and NET release, and lower CD32A and CD16 expression on neutrophils than the "absent" group (Fig.4b,e-h, $\mathrm{P}=0.0001, \mathrm{P}=0.02, \mathrm{P}=0.03, \mathrm{P}=0.005$ and $\mathrm{P}=0.02$, respectively). Additionally, patients in the "strong" group presenting with severe AHR had higher anti-NMBA IgG $(\mathrm{P}=0.003)$, circulating NETs $(\mathrm{P}=0.004)$, neutrophil $\mathrm{CD} 11 \mathrm{~b}$ expression $(\mathrm{P}=0.03)$ and lower neutrophil CD32A expression $(\mathrm{P}=0.0009)$ than those with mild AHR (Fig. S5). These results substantiate the coexistence of IgE- and IgG-dependent mechanisms in AHR patients with strong evidence of IgEdependent anaphylaxis, suggesting that both pathways may contribute to AHR induction and severity. Moreover, the "absent" group, which would usually be categorized as idiopathic in standard care had significantly more circulating NETs, higher expression of CD11b, CD18 (all $\mathrm{P}<0.01)$, and a trend towards lower neutrophil CD32A expression $(\mathrm{P}=0.07)$ but no difference in FceRI expression compared to the control group (Fig.4a,e,h-k). Thus, we document neutrophil activation during NMBA-induced AHR in patients for whom evidence of an IgE-dependent pathway is lacking despite clinical signs compatible with anaphylaxis. These results substantiate the existence of an autonomous IgG-dependent mechanism that could lead to severe reactions, since $26 \%$ of patients in the "absent" group developed severe AHR. An IgG-, Fc $\gamma$ R-, neutrophilpathway may therefore be responsible for NMBA-induced AHR in these patients, provided that anti-NMBA IgG ICs are, indeed, able to trigger neutrophil activation.

\section{Patient-derived anti-NMBA IgG activate neutrophils ex vivo in the presence of NMBA}

Immune complexes formed by specific antibodies binding directly to small chemical entities such as NMBA (with molecular weights of 290, 530 and 929 Da for suxamethonium, rocuronium and atracurium, respectively) are not expected by themselves to be sufficiently large 
or multivalent to activate cells through FcR triggering. Rather, larger molecules such as serum proteins may serve as substrates for NMBA haptenization, but the precise in vivo chemistry remains unknown (36). Indeed, it has been reported that the free fraction of suxamethonium and rocuronium are reduced to $80 \%$ and $54 \%$ after infusion (37). We therefore investigated the potential interaction of these NMBA with abundant human serum proteins using microscale thermophoresis. Rocuronium, but not suxamethonium, was found to interact with human serum albumin (HSA, a known carrier of basic compounds), orosomucoid (a known carrier of acidic and neutral compounds) and transferrin, but not with human IgG1 (Fig. S6a-d). The affinity of all these interactions was very poor, however, necessitating NMBA concentrations in the range of $1-4 \mathrm{mM}$ (Fig. S6e-h), suggesting that at standard intubation doses of rocuronium $(0.6-1.2 \mathrm{mg} / \mathrm{kg}$, estimated to correspond to $\sim 18-36 \mu \mathrm{M}$ in circulation), other molecules may be the partners for NMBA haptenization.

In the absence of an identified protein partner in human serum for rocuronium haptenization, we developed a set of tools, including purified human anti-rocuronium antibodies, rocuronium and succinylmonocholine-albumin bioconjugates and an anti-rocuronium ELISA, to investigate the potential for anti-NMBA IgG ICs to activate Fc $\gamma$ R-expressing neutrophils. Antirocuronium IgG ELISA permitted the identification of 4 patients with high serum concentrations of rocuronium-specific antibodies (Fig.5a), of whom one patient (\#7016; mild AHR following atracurium administration - refer to Table S1) consented for additional blood sampling. Antirocuronium IgG purified from this patient's plasma (Fig.S7a) was confirmed to bind to rocuronium, and also cross-reacted with some other ammonium-containing molecules by ELISA, i.e. morphine antigen- and suxamethonium-bioconjugates, but not other NMBAs or unrelated antigens or allergens (Fig.5b). In addition, binding of these purified IgGs could be dose- 
dependently inhibited using free rocuronium or suxamethonium in solution, but not by the rocuronium-analog molecule $5-\alpha$-dihydrotestosterone $(5 \alpha \mathrm{DHT})$ that lacks quaternary ammonium groups, nor by atracurium, cis-atracurium, pancuronium or vecuronium (Fig. S7b). This confirms a binding preference of these purified IgG to rocuronium and suxamethonium, but no crossreactivity to the other four NMBA tested. Purified anti-rocuronium IgG could form ICs with rocuronium-bioconjugate, and bind to cell transfectants expressing CD16A (Fig.5c). Finally, human neutrophils from healthy controls produced reactive oxygen species (ROS) and released NETs when incubated on plate-bound rocuronium ICs (Fig.5d,e); moreover, they upregulated CD11b and CD66b expression and produced ROS when incubated with soluble rocuronium ICs (Fig. S8). Thus, anti-rocuronium IgG isolated from AHR patients can directly activate human neutrophils in the presence of the culprit NMBA. 


\section{Discussion}

This study provides several converging lines of evidence for the contribution of an IgGFc $\gamma$ R-neutrophil-dependent pathway to human anaphylaxis, using NMBA-induced AHR as a case study. Such a pathophysiological mechanism entails the presence of IgG antibodies against NMBA in patients, leading, together with administered NMBA, to the formation of immune complexes that primarily engage two activating IgG receptors on neutrophils, CD32A/Fc $\gamma$ RIIA and CD16B/FcyRIIIB. Consequently, neutrophils become activated as shown by increased expression of activation markers, degranulation of neutrophil elastase, and elevated circulating NETs. Presumably, such an IgG-dependent pathway leads to the release of the highly potent lipid mediator PAF. It may worsen AHR in concert with IgE-dependent immune activation, or could even be responsible for AHR induction in the absence of IgE-mediated reactions.

Anaphylaxis induction by pathogenic $\operatorname{IgG}$ rather than $\operatorname{IgE}$ antibodies has been demonstrated by many groups in animal models $(15,17,20)$. Moreover, IgG has been implicated in rare clinical studies on anaphylaxis induced by high molecular weight or protein antigens, such as therapeutic antibodies, dextran, protamine or von Willebrand factor $(3-8,38)$. Indeed, patients with elevated anti-infliximab or anti-protamine IgG antibody concentrations have a greater risk to develop anaphylaxis during treatment $(7,8,39)$, suggesting a direct role for $\operatorname{IgG}$ in anaphylaxis pathogenesis. This study is, however, the first report of a potential IgG pathway in human anaphylaxis caused by a low molecular weight $(<1 \mathrm{kDa})$ antigen, i.e. NMBAs. Interestingly, the commonality between previous clinical studies and the current report is that the culprit antigen is administered intravenously in rather large quantities, favoring the formation of ICs in circulation. Our study reports low affinity interactions between rocuronium and prominent human plasma proteins (HSA, orosomucoid, transferrin); yet these $\mathrm{mM}$ range interactions cannot explain 
interactions that form when NMBA circulate at $\mu \mathrm{M}$ concentrations in patients' plasma. Hence the in vivo haptenization chemistry of NMBA remains unknown, along with the identity of putative carrier molecule(s) that may enable NMBA-IgG immune complexes to form and activate Fc $\gamma \mathrm{R}$ expressing myeloid cells.

Thirty-one percent of AHR patients in our study lacked biomarkers of IgE-dependent anaphylaxis, of which $26 \%$ had severe reactions: these data corroborate the existence of alternative, IgE-independent pathways of NMBA-anaphylaxis. An entirely different, and antibody-independent, pathway of anaphylaxis has been reported following cationic drug administration, involving an interaction with Mas-related G-protein coupled Receptor X2 (MRGPRX2) on mast cells $(40,41)$. Nevertheless, such a phenomenon cannot explain the "nonIgE" reactions we observed: among the three culprit NMBAs in our study, only atracurium and rocuronium, but not suxamethonium, could potentially induce such a response and, if so, would result in positivity for some IgE-dependent biomarkers, such as elevated histamine concentrations and positive skin tests (41).

Surprisingly, concentrations of anti-QAM IgG were similar between the AHR population and the controls, although severe AHR patients had higher anti-QAM IgG than mild AHR patients. The latter observation is in line with the principle of dose/concentration-dependent formation of ICs, and may contribute to AHR severity. As quaternary ammonium groups and similar moieties are present in a large number of household products, hair colorations and anti-cough medication (42), generalized positivity for anti-QAM IgG likely reflects exposure of the general population to these compounds. It remains unclear, however, why controls with high anti-QAM IgG do not develop AHR following NMBA infusion. Anti-QAM IgG antibodies could have different affinities in patients versus controls, which could affect both their capacity to form ICs in the presence of 
NMBA, and to compete with IgE for NMBA binding (43). Supporting this notion, this cohort demonstrates a positive correlation between high concentrations of anti-QAM $\operatorname{IgE}$ and $\operatorname{IgG}$, both in patients and in the rare controls with positive anti-QAM IgE. Using a combination of clinically validated tests, and research assays not yet validated for clinical practice, our analyses revealed that specific IgE concentrations for suxamethonium, atracurium and rocuronium also tended to be higher in samples initially determined as high for anti-QAM IgE. This may also be the case for IgG, particularly for suxamethonium-specific IgG, even if no threshold of "positivity" for antiNMBA IgG has ever been established (Fig. S1).

Neutrophils from severe AHR patients early after reaction onset demonstrated increased expression of activation markers CD18, CD11b and CD66b compared to mild AHR patients. These data reveal, for the first time, the activation of neutrophils during NMBA-induced AHR in humans, and correlate the severity of AHR with elevated neutrophil-specific circulating markers: elastase and NETs. A role for neutrophils in anaphylaxis has previously been reported in animal models (19, 44-46). Circulating NETs and expression of CD11b and CD18 were also higher in mild AHR patients than controls, perhaps indicating that these are more sensitive markers of neutrophil activation than circulating elastase or CD66b expression. Considering patients subgroups according to the NMBA received, an increase of $\mathrm{CD} 18$ and $\mathrm{CD} 11 \mathrm{~b}$ on neutrophils remained highly significant when examining suxamethonium-infused patients, but was less apparent in atracuriuminfused patients. Antibody-independent alternative mechanisms reported for AHR induction by atracurium (47) may be confounding factors in the latter analysis. Two key findings strongly suggest the direct activation of neutrophils as a consequence of their interaction with NMBA-IgG ICs. First, the downregulation of FcrR CD32A and CD16B on neutrophils from AHR patients, and second the in vitro demonstration that NMBA-IgG ICs induce neutrophils to produce ROS 
and NETs. Less pronounced CD32A downregulation on monocytes from severe AHR patients suggests concomitant monocyte activation directly by NMBA-IgG complexes, of lesser magnitude, which may also contribute to mediator release and AHR induction/severity. Indeed, stimulation of neutrophils and monocytes from CD32A transgenic mice via CD32A results in the production of PAF and other lipid mediators (25) and more generally, engagement of CD32A by IgG-ICs results in activation of cells in vitro and in vivo $(48,49)$, including NET release $(50)$. When analyzing suxamethonium-infused or atracurium-infused patients, only the downregulation of CD32A on neutrophils remained highly significant (Fig. S2). Altogether, these findings suggest CD32A as a marker for IgG-dependent severe AHR, at least those induced by suxamethonium and atracurium.

The relative contribution of cell subsets to anaphylaxis has been described using depletion studies in mouse models $(15,17,19,51)$, and is highly dependent on the model used $(23,52,53)$. Our previous reports using a mouse model expressing human Fc $\gamma$ Rs (CD32A, CD32B, CD16A, CD16B) in place of mouse Fc $\gamma$ Rs showed neutrophils to be predominant (24) whereas using mice expressing only human CD32A showed neutrophils and monocytes to contribute equally (25). The very high co-expression of $\mathrm{CD} 16 \mathrm{~B}$ with $\mathrm{CD} 32 \mathrm{~A}$ on neutrophils may favor neutrophil activation over monocytes during the induction phase of anaphylaxis, and explain both the results obtained in mice (24) and the clinical results presented herein. IgG-dependent pathways may thus preferentially trigger neutrophils whereas IgE-dependent pathways may preferentially trigger mast cells $(9,54)$. The main anaphylactogenic mediators reported for these two modalities are PAF (19, $20)$ and histamine $(30,55)$, respectively. Even though neutrophils represent by far the largest cell population in circulation and a major source of PAF, most cell subsets that have been proposed to contribute to anaphylaxis can produce PAF, including IgG-IC stimulated monocytes and basophils, 
and IgE-stimulated mast cells (56-58). The reduction in PAF-AH activity we observed in severe AHR patients indirectly substantiates elevated PAF concentrations during NMBA-AHR. In addition, we observed consumption of complement components during severe AHR, suggesting that complement may also contribute to the severity of anaphylaxis (59-61) by potentiating myeloid cell activation, in conjunction with PAF, histamine and other mediators. This first observation needs however to be confirmed in additional studies as a complement consumption could be also a consequence of general anesthesia (62).

Circulating DNA-MPO complexes are markers of NETs and here we identify that their concentrations in circulation are associated with AHR severity. While NETs have been implicated in some allergic contexts, such as asthma (63), this is the first report to describe netosis in anaphylaxis. NETs may contribute to AHR directly, by toxic effects of their components on tissues and epithelia (64), thereby impeding organ function. Alternatively, the involvement of NETs in AHR may be via activation of the coagulation contact system (65), which has been linked to the severity of anaphylaxis (66). Elevated amounts of circulating NETs were detected in patients during the acute phase of AHR and remained even 6-8 weeks later, whether considering all patients or subgroups infused with suxamethonium only or with atracurium only. The maintenance of elevated NET concentrations long after clinical remission could represent a biomarker of persistent inflammation after the initial systemic reaction. Not only NET concentrations but also expression of neutrophil activation markers (CD11b, CD18) were elevated in patients at the time of the followup visit 6-8 weeks post-AHR, a finding which was also significant when analyzing only patients infused with suxamethonium. Such a long-lasting effect of AHR on neutrophil activation status is in accordance with one study, which found elevated transcription of neutrophil-related genes in patients with a previous episode of anaphylaxis (67). 
Our study carries some limitations due to the design and observational nature. First, we report here a consistent correlation between several IgG-dependent markers and anaphylaxis severity, but we cannot prove direct causality between neutrophil activation and anaphylaxis. Second, basophils from severe AHR patients demonstrated significantly lower IgE receptor (FceRI) expression during the anaphylaxis event than during the allergology visit 6-8 weeks postAHR. Whereas fast downregulation of FceRI after IgE-allergen triggering has been reported on rat and mouse mast cells (68), reports do not support the existence of such a consequence on human basophils $(69,70)$. This discrepancy might relate to a different behavior of human basophils in vivo than in vitro, to the nature of allergen aggregating the IgE-FceRI complex, to Fc $\gamma$ Rs dragging IgE-bound FceRI inside the basophil after interaction with IgG-allergen complexes, or even an unknown bystander effect of anaphylaxis. Third, although we classified our patients according to the likelihood of an IgE-dependent reaction, we did not account for other reactions, e.g. pharmacological activation of mast cells (41) or non-specific histamine release (71), which can represent alternative mechanisms of anaphylaxis induction in the absence of specific $\operatorname{IgE}$.

In conclusion, this work defines a clinically-relevant pathway of NMBA-induced AHR, involving IgG, IgG-receptors and neutrophils. This pathway may co-exist with the classical IgEdependent pathway, and compound the severity of IgE-associated "allergic" AHR. It could also be responsible for AHR in patients with no markers of IgE-dependent immune activation; previously designated "non-allergic" AHR (72). Furthermore, in patients showing strong evidence for engagement of the IgE-dependent pathway, IgG markers remained strongly associated with anaphylaxis severity, indicating that simultaneous engagement of IgG- and IgE-dependent mechanisms may occur during human anaphylaxis. Our data suggest that these pathways can combine to worsen AHR. We predict that our findings can be extrapolated to most AHR wherein 
the culprit allergen(s) are present in the circulation. Evaluation of specific IgG markers in the clinical AHR diagnostic process may clarify diagnosis and be a way to risk-stratify patients. Our results also pave the way for novel therapeutic interventions, particularly aiming at IgG receptor blockade. 


\section{[ Materials and Methods : ]}

\section{Study design}

The multicentric NASA ("Neutrophil Activation in Systemic Anaphylaxis") study involved 11 Anaesthesia and Intensive Care departments in the Ile-de-France region in France (https://clinicaltrials.gov/ct2/show/NCT01637220). The study was approved for all centers by an Institutional Review Board (ethical committee "Comité de Protection des Personnes Ile-de-France 1", reference 2012-avril-12880), and registered before the first inclusion at ClinicalTrials.gov (Identifier: NCT0163722). The design of the study and detailed clinical characteristics of the patients are described elsewhere (33). Briefly, patients with clinical signs consistent with intraanaesthetic AHR to NMBA were prospectively included between November 2012 and June 2014. Venous blood samples were collected at 30 minutes and 2 hours following the onset of the AHR and during the allergology-anaesthesia visit 6-8 weeks post-AHR. At this visit, immediate reading intra-dermal tests against suspected culprit agents were performed. Clinical, biological and demographic patient data are summarized in Tables 1 and 2. Patients were classified a posteriori in grades of severity according to the Ring and Messmer classification (73) by two independent intensive care unit experts. A severe AHR was defined as a grade 3 or 4 (severe organ failure or cardiac/respiratory arrest) while a mild AHR was defined as a grade 1 or 2. Classifications of AHR according to evidence of an IgE-mediated pathway, i.e. "strong", "equivocal" or "absent", were established a posteriori by a consortium of six experts taking in account clinical symptoms, tryptase, histamine, specific IgE and results of skin tests. For each patient included, a control was recruited: a patient undergoing surgery with NMBA without any signs consistent with intraanaesthetic AHR. Controls were matched to patients for age ( \pm 5 years), sex, NMBA used, type of surgical procedure and infectious status. Written informed consent was obtained from the patients 
or their legal representative before study inclusion. By French law, in case of impaired decisionmaking capacity without a legal representative available at the time of inclusion, the patient's informed consent could be obtained after enrollment ("emergency inclusion"). Venous blood samples were collected 30 minutes after anesthesia for controls.

\section{Classical anaphylaxis parameters}

As part of standard care procedures, the following circulating parameters were assessed as previously described (35): histamine (EIA, Immunotech, Beckman Coulter, Brea, California, USA) and tryptase (FEIA, ImmunoCAP 250 Phadia, Thermofisher ${ }^{\circledR}$, Waltham, Massachusetts, USA) in plasma and anti-quaternary ammonium-specific IgE (FEIA, ImmunoCAP 250 Phadia, Thermofisher ${ }^{\circledR}$, Waltham, Massachusetts, USA) in serum. A value less than $0.35 \mathrm{kU} / \mathrm{L}$ of specific IgE was considered negative, as recommended (35). Tryptase concentrations two hours following AHR were considered elevated when greater than $(1.2 \times$ [baseline tryptase $\left.]+2 \mu \mathrm{g} . \mathrm{L}^{-1}\right)$ as recently recommended (74). A histamine concentration above $20 \mathrm{nmol} \cdot \mathrm{L}^{-1} 30$ minutes following AHR was considered elevated. Data is summarized in Table S2.

In addition, specific IgE concentrations for suxamethonium were assessed using the clinicallyvalidated suxamethonium ImmunoCAP (Phadia ImmunCAP\#c202). Moderately sensitive ImmunoCAPs for atracurium (75) and rocuronium (76) were obtained as experimental prototypes made for research use (Phadia AB, Uppsala, Sweden). Of note atracurium ImmunoCAP is prepared using tetrahydropapaverine modified with $\beta$-propiolactone, as a surrogate for atracurium, before conjugation to poly L-lysine (atracurium ImmunoCAP conjugate) (77).

To avoid commonly reported problems with the diagnosis of IgE-dependent reactions (false negative tryptase/histamine measurements), blood sampling was carefully and uniformly 
performed across the study and there was no difference in delay before blood sampling between patients with a negative or a positive plasma tryptase (Table 2). Specific IgE were analyzed on a unique instrument, and skin tests performed and analyzed by only three allergologists.

\section{Complement measurements}

Complement haemolysis 50\% (CH50) activity and complement fractions $\mathrm{C} 3$ and $\mathrm{C} 4$ were determined by turbidimetry on a SPA + analyzer (Binding Site, Birmingham, UK) according to the manufacturer's instructions and standard practice of the laboratory.

\section{Human plasma protein interactions with NMBA}

Protein binding of NMBA was studied by microscale thermophoresis (MST) measurements on a Monolith LabelFree (NanoTemper, Gmbh). Rocuronium pre-dilutions were prepared by 16-fold 2:1 serial dilutions of compound in PBS buffer to yield a range of $8 \mathrm{mM}$ to $18 \mu \mathrm{M}$ in a final volume of $10 \mu \mathrm{L}$. Lower concentrations were studied in preliminary experiments and did not show any binding. Rocuronium dilutions were mixed with $10 \mu \mathrm{L}$ of target proteins (human serum albumin (HSA), transferrin, orosomucoid and $\operatorname{IgG} 1$ ), at $2 \mu \mathrm{M}$ final each. Samples were loaded in standard treated capillaries (NanoTemper, LLC, Munich, Germany). Experiments were performed with MST power medium (20\%) and LED intensity of 10 or $20 \%$. Each experiment was performed in duplicate and reproduced 3 times. Data was analyzed using MO Affinity Analysis software (NanoTemper Technologies).

\section{Specific IgG measurement}


Anti-QAM IgG concentrations were measured using an adaptation of the ImmunoCAP ${ }^{\circledR}$ matrix used to measure anti-QAM IgE concentrations (considered the most sensitive marker for IgEinduced NMBA-AHR(35)) (Phadia, Thermofischer, Waltham, Massachusetts, USA). As no reference interval exists for this parameter, raw values were evaluated relative to an IgG calibration curve and expressed in $\mu \mathrm{g} / \mathrm{mL}$. The secondary antibody used to detect IgG in the ImmunoCAP is a mouse monoclonal IgG1 antibody binding all four human IgG subclasses (Phadia). The human IgE detection reagent was replaced with the same monoclonal anti-human $\operatorname{IgG}$ reagent in the clinically-validated suxamethonium ImmunoCAP (Phadia ImmunCAP c202), or research-grade atracurium ImmunoCAP and rocuronium ImmunoCAP (Phadia AB, Uppsala, Sweden) to detect anti-suxamethonium, -atracurium or -rocuronium IgG, respectively.

\section{Flow cytometric analysis of Fc receptors and activation markers}

Heparinized blood sampled during NMBA-induced AHR and at the patient's allergy visit, as well as blood from anesthetized matched controls, was immediately transported from the site of blood collection to the Institut Pasteur (Paris, France). Upon receipt, RBC were lysed using ACK buffer, white blood cells washed in PBS/1\% Bovine Serum Albumin (BSA) / 2 mM EDTA and incubated with indicated antibodies for $30 \mathrm{~min}$ at $4^{\circ} \mathrm{C}$ (Table S3). Cells were washed and acquired on a MACSQuant flow cytometer (Miltenyi Biotech ${ }^{\circledR}$, Bergisch Gladbach, Germany) and analyzed using FlowJo software (Treestar, Ashland, Oregon, USA). Blood samples showing signs of clotting or hemolysis, as well as samples during which processing problems occurred, were excluded from the analysis. White Blood Cells (WBC) populations were identified as neutrophils

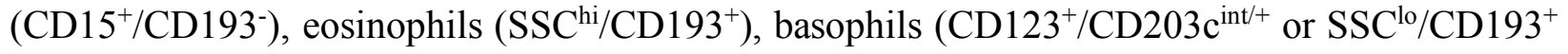
for Fig. 2), monocytes (CD14 $\left.{ }^{+} / \mathrm{CD}^{-}\right)$, B cells (CD19 $\left.{ }^{+} / \mathrm{CD}^{-}\right)$, $\mathrm{T}$ cells $\left(\mathrm{CD}^{+} / \mathrm{CD}^{-} 6^{-}\right)$or $\mathrm{NK}$ cells $\left(\mathrm{CD} 6^{+} / \mathrm{CD}^{-}\right)$. The expression value for each marker was determined as the difference between 
the geometric mean of the fluorescence intensity of the marker and the geometric mean of the matched isotype control ( $\Delta$ GeoMean).

\section{Circulating neutrophil extracellular traps (NETs) quantification}

In order to quantify circulating NETs, DNA-myeloperoxidase (DNA-MPO) complexes were measured in serum samples using a capture ELISA described elsewhere (33). Briefly, 96-well microtitre plates were coated overnight with $5 \mu \mathrm{g} / \mathrm{mL}$ of rabbit anti-human MPO antibody (Millipore $^{\circledR}$, Billerica, Massachusetts, USA). After blocking with 2\% BSA, serum samples were added together with a peroxidase-labeled anti-DNA monoclonal antibody (component 2 of the Cell Death ELISA kit, Roche). After incubation, the peroxidase substrate was added for $40 \mathrm{~min}$ at $37^{\circ} \mathrm{C}$. Results are expressed as optical absorbance measured at $405 \mathrm{~nm}$ in a spectrophotometer.

\section{Elastase quantification}

Plasma concentrations of human elastase were measured using a commercial ELISA kit (Abcam ${ }^{\circledR}$, Cambridge, UK) according to the manufacturer's instructions.

\section{PAF-acetyl hydrolase quantification}

The activity of the enzyme that hydrolyzes and inactivates PAF (PAF-acetyl-hydrolase, PAF-AH) inversely correlates with PAF concentrations in human serum(31, 78). Extracellular enzymatic activity of PAF-AH was measured in plasma samples using a commercial chromogenic kinetic kit (Cayman Chemical, Ann Harbor, Michigan, USA) according to the manufacturer's instructions. Briefly, hydrolysis of a modified substrate (2-thio-PAF) by the PAF-AH contained in plasma released a colored product after conjugation with 5,5'-dithiobis-2-nitrobenzoic acid (DTNB). Optical absorbance at $405 \mathrm{~nm}$ was measured once every minute to obtain 8 time-points. Results 
are expressed in $\mu \mathrm{mol} / \mathrm{min} / \mathrm{mL}$; calculated using the following formula: [PAF-AH $(\mu \mathrm{mol} / \mathrm{min} / \mathrm{mL})$ $=\Delta \mathrm{A} 405 \mathrm{~min}-1 / 10 \mathrm{mM}-1 \mathrm{X} 0.225 \mathrm{ml} / 0.01 \mathrm{ml} \mathrm{X}$ sample dilution]

\section{Production and characterization of rocuronium and suxamethonium bioconjugates}

Hapten-protein couplings were performed using active ester derivatives of rocuronium or suxamethonium and HSA (Human Serum Albumin) or BSA (Bovine Serum Albumin) as the carrier protein.

- For the rocuronium derivative, a carboxylate function was first introduced by adding succinic anhydride to rocuronium bromide in the presence of 4-(dimethylamino)-pyridine in pyridine. After stirring overnight at room temperature under argon, the solvent was removed under vacuum. The crude compound was purified by reverse-phase flash chromatography (linear gradient $10-80 \%$ of $\mathrm{CH}_{3} \mathrm{CN}+0.1 \%$ trifluoroacetic acid in $\mathrm{H}_{2} \mathrm{O}+0.1 \%$ trifluoroacetic acid over 60 minutes), resulting in a rocuronium derivative with a carboxylic acid at the 3-position of the steroid scaffold ( $81 \%$ yield). The compound was characterized by mass spectrometry (Q-Tofmicro ${ }^{\mathrm{TM}}$ spectrometer (Micromass)) with an electrospray ionization (positive mode) source (Waters, France) $\left(\mathrm{C}_{36} \mathrm{H}_{57} \mathrm{~N}_{2} \mathrm{O}_{7}\right.$ calcd. 629.4166, 315.2122; $\left.\left.m / z 629.4183[\mathrm{M}+\mathrm{H}]^{+}, 315.2085[\mathrm{M}+2 \mathrm{H}]^{2+}\right)\right)$ and by nuclear magnetic resonance analysis (Table S4).

All quantities of products used in the protocol were calculated relative to the carrier protein. The functionalized rocuronium (300 equivalent) was dissolved in $0.1 \mathrm{M} \mathrm{MES}+0.5 \mathrm{M} \mathrm{NaCl}$ buffer $\mathrm{pH}$ 5.6 and combined with 1-ethyl-3-(3-dimethylaminopropyl)carbodiimide (1000 equivalent) in the presence of N-hydroxysulfosuccinimide (400 equivalent). After 5 minutes stirring at room temperature, $\mathrm{pH}$ was adjusted to 7.2 with $2 \mathrm{~N} \mathrm{NaOH}$. This solution was progressively added to the carrier protein dissolved in PBS $1 \mathrm{X} \mathrm{pH} \mathrm{7.2.} \mathrm{After} 3$ hours of gentle agitation at room temperature and extensive dialysis in PBS, the conjugated proteins were obtained at 50\% yield. 
For the suxamethonium derivative, choline chloride was treated as previously reported (79) to generate a carboxylated intermediate succinyl-monocholine ( $93 \%$ yield), that was then conjugated with the proteins as described above (but at 600 equivalent relative to the carrier protein). The resulting conjugates were obtained at $80-85 \%$ yield.

Exact measurement of the concentration of the bioconjugates was achieved by quantitative aminoacid analysis using a Beckman 6300 analyzer after hydrolysis with $6 \mathrm{~N} \mathrm{HCl}$ at $110^{\circ} \mathrm{C}$ for 20 hours. The average density of conjugated rocuronium and suxamethonium derivatives was evaluated by matrix-assisted laser desorption/ionization time-of-flight mass spectrometry and was found to be $22 \pm 10$ and $42 \pm 10$, respectively, for the HSA conjugates.

\section{Affinity purification on rocuronium of human polyclonal IgG}

Rocuronium, but not atracurium nor suxamethonium, possesses chemical groups that can be targeted for chemical coupling to carrier molecules. Rocuronium was thus the only NMBA that could be coupled in vitro as a whole molecule, and we therefore chose to use rocuronium conjugates to isolate NMBA-specific IgG. BSA-rocuronium or BSA were coupled overnight to CNBr-Activated sepharose 4 Fast Flow (General Electrics ${ }^{\circledR}$, Buckinghamshire, England) according to the manufacturer's recommendations. BSA sepharose beads were packed in PolyPred Chromatography Columns (Bio-Rad ${ }^{\circledR}$, Hercules, California, US). Human serum, after centrifugation and filtration $(0.45 \mu \mathrm{m})$, was passed twice through the BSA column. The flowthrough was then incubated overnight with the BSA-rocuronium sepharose beads with agitation. Elution was performed with $0.12 \mathrm{M}$ glycine buffer, $\mathrm{pH} 3.0$, eluted antibody fractions were dialyzed in $0.1 \mathrm{M}$ Tris buffer $\mathrm{pH} 8.0$ (optimized buffer determined by Dynamic Light Scattering analyses). ELISA: Maxisorp 96-well plates were coated with $5 \mu \mathrm{g} / \mathrm{mL}$ of carrier proteins, NMBA-conjugated carrier protein or allergens, incubated with serial dilutions of human antibodies purified on 
rocuronium affinity columns, and revealed with HRP-conjugated anti-human IgG secondary antibodies (Jackson Immunoresearch) and OPD (Sigma).

Competition ELISA: 96-well plates were coated with $5-10 \mu \mathrm{g} / \mathrm{mL}$ of rocuronium-(20)-HSA. Human antibodies purified on rocuronium affinity columns were mixed at $0.9 \mu \mathrm{g} / \mathrm{mL}$ with serial dilutions (starting at $5 \mathrm{mM}$ ) of different NMBAs or chemical analogs. Binding of human IgG was revealed with HRP-conjugated anti-human IgG secondary antibodies (Jackson Immunoresearch) and OPD (Sigma).

\section{Ex vivo neutrophil activation by [anti-rocuronium IgG - rocuronium HSA bioconjugate] immune complexes and drugs used for anaphylaxis treatment.}

Neutrophils from healthy donors were purified using MACSXpress Neutrophil isolation kit (Miltenyi Biotech ${ }^{\circledR}$, Bergisch Gladbach, Germany, which gave a purity routinely over $98 \%$. Purified neutrophils were suspended at $1.5 \times 10^{6} \mathrm{cells} / \mathrm{mL}$ in Hank's Balanced Salt Solution (HBSS) and $100 \mu \mathrm{L}$ of cells were seeded 96-well plates for stimulation with plate-bound ICs or soluble ICs. Plate-bound ICs were prepared by coating 96 well plates with rocuronium-coupled Human Serum Albumin (HSA-Roc; $200 \mu \mathrm{g} / \mathrm{mL}$ ) followed by incubation with patient-derived purified antirocuronium human polyclonal $\operatorname{IgG}(50 \mu \mathrm{g} / \mathrm{mL})$. Soluble ICs were prepared by mixing HSA-(20)Roc $(5 \mu \mathrm{g} / \mathrm{mL})$ with anti-rocuronium $\operatorname{IgG}(100 \mu \mathrm{g} / \mathrm{mL})$. Positive controls were obtained by coating with ovalbumin $(200 \mu \mathrm{g} / \mathrm{mL})$, followed by rabbit polyclonal anti-ovalbumin antibodies $(50 \mu \mathrm{g} / \mathrm{mL})$. Negative controls were obtained by coating antigen alone, without further incubation with antibodies. Oxidative burst (ROS release) and netosis were measured as previously described (33). Briefly, oxidative burst was measured by chemoluminescence at $37^{\circ} \mathrm{C}$ for $1 \mathrm{~h}$ after addition of luminol (final concentration $50 \mu \mathrm{M}$ ). Results are expressed as peak luminescence value. Netosis was measured by cell-free DNA (cf DNA) release using Sytox Green DNA probe 
(Thermofischer ${ }^{\circledR}$, final concentration $5 \mu \mathrm{M}$ ) at $37^{\circ} \mathrm{C}$ for $300 \mathrm{~min}$. Results are expressed as $530 \mathrm{~nm}$ fluorescence normalized for baseline and unstimulated controls. Both luminescence and fluorescence were read on a microplate reader (TristarTM LB941, Berthold). Neutrophil activation was also tested following incubation in solution with epinephrine, ephedrine, methylprednisolone, atropine, and various resuscitation fluids, using serial dilutions from drugs vials obtained from an intensive care unit.

\section{Statistical analyses}

Paired comparisons (between patients and matched controls or between inclusion and follow-up visits) were performed with a paired Wilcoxon signed rank test. Sub-groups of patients were compared with a Mann-Whitney U test. Statistical tests were bilateral and a type I error was fixed at 5\%. Statistical analyses were performed with GraphPad Prism version 5.0 and 7.0 (GraphPad Software Inc., La Jolla, USA), R version 3.0.2 software (R foundation for Statistical Computing, Vienna, Austria), and SAS 9.2 (SAS Institute, Cary, North Carolina, USA). 


\section{Supplementary Materials:}

\section{Supplementary Materials and Methods}

\section{Supplementary Figures}

Fig. S1. Anti-QAM, -suxamethonium, -atracurium and -rocuronium IgE and IgG ImmunoCAP Fig. S2. NMBA-dependent analyses of FcR and CD11b-CD18 expression

Fig. S3. Complement pathway CH50, C3 and C4 during AHR versus V2

Fig. S4. Effect of resuscitation fluids and drugs used during AHR on neutrophil activation

Fig. S5. IgG markers in patients with strong evidence of IgE pathway

Fig. S6. Microscale thermophoresis analyses of rocuronium and suxamethonium protein partners

Fig. S7. Characterization of patient-derived anti-rocuronium IgG

Fig. S8. Human neutrophil activation by soluble NMBA-anti-NMBA IgG immune complexes

\section{Supplementary Tables}

Table S1. Individual values of QAM $\operatorname{IgE}(\mathrm{kU} / \mathrm{L})$ and QAM $\operatorname{IgG}(\mu \mathrm{g} / \mathrm{mL})$ represented for casecontrols pairs.

Table S2: Tryptase and histamine measurements.

Table S3: Flow cytometry antibodies

Table S4: Nuclear magnetic resonance data of carboxylated rocuronium in $\mathrm{D}_{2} \mathrm{O}$ 


\section{References and Notes:}

1. J. H. Lee, J. W. Kim, D. K. Kim, H. S. Kim, H. J. Park, D. K. Park, A. R. Kim, B. Kim, M. A. Beaven, K. L. Park, Y. M. Kim, W. S. Choi, The Src family kinase Fgr is critical for activation of mast cells and IgE-mediated anaphylaxis in mice. J Immunol 187, 18071815 (2011).

2. S. G. Brown, K. E. Blackman, R. J. Heddle, Can serum mast cell tryptase help diagnose anaphylaxis? Emerg Med Australas 16, 120-124 (2004).

3. A. Cheifetz, M. Smedley, S. Martin, M. Reiter, G. Leone, L. Mayer, S. Plevy, The incidence and management of infusion reactions to infliximab: a large center experience. Am J Gastroenterol 98, 1315-1324 (2003).

4. A. P. Schmidt, H. F. Taswell, G. J. Gleich, Anaphylactic transfusion reactions associated with anti-IgA antibody. N Engl J Med 280, 188-193 (1969).

5. H. Hedin, W. Richter, K. Messmer, H. Renck, K. G. Ljungstrom, H. Laubenthal, Incidence, pathomechanism and prevention of dextran-induced anaphylactoid / anaphylactic reactions in man. Dev Biol Stand 48, 179-189 (1980).

6. L. Bergamaschini, P. M. Mannucci, A. B. Federici, R. Coppola, S. Guzzoni, A. Agostoni, Posttransfusion anaphylactic reactions in a patient with severe von Willebrand disease: role of complement and alloantibodies to von Willebrand factor. J Lab Clin Med 125, 348-355 (1995).

7. C. Steenholdt, M. Svenson, K. Bendtzen, O. O. Thomsen, J. Brynskov, M. A. Ainsworth, Acute and delayed hypersensitivity reactions to infliximab and adalimumab in a patient with Crohn's disease. J Crohns Colitis 6, 108-111 (2012).

8. M. E. Weiss, D. Nyhan, Z. K. Peng, J. C. Horrow, E. Lowenstein, C. Hirshman, N. F. Adkinson, Jr., Association of protamine IgE and IgG antibodies with life-threatening reactions to intravenous protamine. $N$ Engl J Med 320, 886-892 (1989).

9. F. D. Finkelman, M. V. Khodoun, R. Strait, Human IgE-independent systemic anaphylaxis. J Allergy Clin Immunol 137, 1674-1680 (2016).

10. H. C. Oettgen, T. R. Martin, A. Wynshaw-Boris, C. Deng, J. M. Drazen, P. Leder, Active anaphylaxis in IgE-deficient mice. Nature 370, 367-370 (1994).

11. D. Dombrowicz, V. Flamand, I. Miyajima, J. V. Ravetch, S. J. Galli, J. P. Kinet, Absence of Fc epsilonRI alpha chain results in upregulation of Fc gammaRIII-dependent mast cell degranulation and anaphylaxis. Evidence of competition between Fc epsilonRI and Fc gammaRIII for limiting amounts of FcR beta and gamma chains. $J$ Clin Invest 99, 915 925 (1997).

12. I. Miyajima, D. Dombrowicz, T. R. Martin, J. V. Ravetch, J. P. Kinet, S. J. Galli, Systemic anaphylaxis in the mouse can be mediated largely through IgG1 and Fc gammaRIII. Assessment of the cardiopulmonary changes, mast cell degranulation, and death associated with active or IgE- or IgG1-dependent passive anaphylaxis. J Clin Invest 99, 901-914. (1997).

13. I. H. Choi, Y. M. Shin, J. S. Park, M. S. Lee, E. H. Han, O. H. Chai, S. Y. Im, T. Y. Ha, H. K. Lee, Immunoglobulin E-dependent active fatal anaphylaxis in mast cell-deficient mice. J Exp Med 188, 1587-1592 (1998).

14. F. D. Finkelman, Anaphylaxis: lessons from mouse models. J Allergy Clin Immunol 120, 506-515; quiz 516-507 (2007). 
15. H. Beutier, C. M. Gillis, B. Iannascoli, O. Godon, P. England, R. Sibilano, L. L. Reber, S. J. Galli, M. S. Cragg, N. Van Rooijen, D. A. Mancardi, P. Bruhns, F. Jonsson, IgG subclasses determine pathways of anaphylaxis in mice. J Allergy Clin Immunol 139, 269280 e267 (2017).

16. M. V. Khodoun, Z. Y. Kucuk, R. T. Strait, D. Krishnamurthy, K. Janek, C. D. Clay, S. C. Morris, F. D. Finkelman, Rapid desensitization of mice with anti-

FcgammaRIIb/FcgammaRIII mAb safely prevents IgG-mediated anaphylaxis. J Allergy Clin Immunol 132, 1375-1387 (2013).

17. R. T. Strait, S. C. Morris, M. Yang, X. W. Qu, F. D. Finkelman, Pathways of anaphylaxis in the mouse. $J$ Allergy Clin Immunol 109, 658-668 (2002).

18. D. Jiao, Y. Liu, X. Lu, B. Liu, Q. Pan, Y. Liu, Y. Liu, P. Zhu, N. Fu, Macrophages are the dominant effector cells responsible for IgG-mediated passive systemic anaphylaxis challenged by natural protein antigen in BALB/c and C57BL/6 mice. Cell Immunol 289, 97-105 (2014).

19. F. Jönsson, D. A. Mancardi, Y. Kita, H. Karasuyama, B. Iannascoli, N. Van Rooijen, T. Shimizu, M. Daëron, P. Bruhns, Mouse and human neutrophils induce anaphylaxis. $J$ Clin Invest 121, 1484-1496 (2011).

20. Y. Tsujimura, K. Obata, K. Mukai, H. Shindou, M. Yoshida, H. Nishikado, Y. Kawano, Y. Minegishi, T. Shimizu, H. Karasuyama, Basophils play a pivotal role in immunoglobulin-G-mediated but not immunoglobulin-E-mediated systemic anaphylaxis. Immunity 28, 581-589 (2008).

21. P. Bruhns, F. Jonsson, Mouse and human FcR effector functions. Immunol Rev 268, 2551 (2015).

22. R. Molfetta, F. Gasparrini, A. Santoni, R. Paolini, Ubiquitination and endocytosis of the high affinity receptor for IgE. Mol Immunol 47, 2427-2434 (2010).

23. M. V. Khodoun, R. Strait, L. Armstrong, N. Yanase, F. D. Finkelman, Identification of markers that distinguish IgE- from IgG-mediated anaphylaxis. Proc Natl Acad Sci US A 108, 12413-12418 (2011).

24. C. M. Gillis, F. Jonsson, D. A. Mancardi, N. Tu, H. Beutier, N. Van Rooijen, L. E. Macdonald, A. J. Murphy, P. Bruhns, Mechanisms of anaphylaxis in human low-affinity IgG receptor locus knock-in mice. J Allergy Clin Immunol 139, 1253-1265 e1214 (2017).

25. F. Jönsson, D. A. Mancardi, W. Zhao, Y. Kita, B. Iannascoli, H. Khun, N. van Rooijen, T. Shimizu, L. B. Schwartz, M. Daëron, P. Bruhns, Human FcgammaRIIA induces anaphylactic and allergic reactions. Blood 119, 2533-2544 (2012).

26. V. Papayannopoulos, Neutrophil extracellular traps in immunity and disease. Nat Rev Immunol 18, 134-147 (2018).

27. G. Z. Lotner, J. M. Lynch, S. J. Betz, P. M. Henson, Human neutrophil-derived platelet activating factor. J Immunol 124, 676-684 (1980).

28. E. Jouvin-Marche, E. Ninio, G. Beaurain, M. Tence, P. Niaudet, J. Benveniste, Biosynthesis of Paf-acether (platelet-activating factor). VII. Precursors of Paf-acether and acetyl-transferase activity in human leukocytes. J Immunol 133, 892-898 (1984).

29. S. Ishii, T. Kuwaki, T. Nagase, K. Maki, F. Tashiro, S. Sunaga, W. H. Cao, K. Kume, Y. Fukuchi, K. Ikuta, J. Miyazaki, M. Kumada, T. Shimizu, Impaired anaphylactic responses with intact sensitivity to endotoxin in mice lacking a platelet-activating factor receptor. $J$ Exp Med 187, 1779-1788 (1998). 
30. K. Arias, M. Baig, M. Colangelo, D. Chu, T. Walker, S. Goncharova, A. Coyle, P. Vadas, S. Waserman, M. Jordana, Concurrent blockade of platelet-activating factor and histamine prevents life-threatening peanut-induced anaphylactic reactions. J Allergy Clin Immunol 124, 307-314, 314 e301-302 (2009).

31. P. Vadas, M. Gold, B. Perelman, G. M. Liss, G. Lack, T. Blyth, F. E. Simons, K. J. Simons, D. Cass, J. Yeung, Platelet-activating factor, PAF acetylhydrolase, and severe anaphylaxis. $N$ Engl J Med 358, 28-35 (2008).

32. P. Vadas, B. Perelman, G. Liss, Platelet-activating factor, histamine, and tryptase levels in human anaphylaxis. J Allergy Clin Immunol 131, 144-149 (2013).

33. A. Gouel-Cheron, L. de Chaisemartin, F. Jonsson, P. Nicaise-Roland, V. Granger, A. Sabahov, M. T. Guinnepain, S. Chollet-Martin, P. Bruhns, C. Neukirch, D. Longrois, N. s. group, Low end-tidal $\mathrm{CO} 2$ as a real-time severity marker of intra-anaesthetic acute hypersensitivity reactions. Br J Anaesth 119, 908-917 (2017).

34. H. Chou, M. F. Tam, S. S. Lee, R. B. Tang, T. H. Lin, H. Y. Tai, Y. S. Chen, H. D. Shen, Asp159 is a critical core amino acid of an IgE-binding and cross-reactive epitope of a dust mite allergen Der f 7. Mol Immunol 48, 2130-2134 (2011).

35. D. Laroche, S. Chollet-Martin, P. Leturgie, L. Malzac, M. C. Vergnaud, C. Neukirch, L. Venemalm, J. L. Gueant, P. N. Roland, Evaluation of a new routine diagnostic test for immunoglobulin e sensitization to neuromuscular blocking agents. Anesthesiology 114, 91-97 (2011).

36. B. A. Baldo, M. M. Fisher, N. H. Pham, On the origin and specificity of antibodies to neuromuscular blocking (muscle relaxant) drugs: an immunochemical perspective. Clin Exp Allergy 39, 325-344 (2009).

37. J. J. Roy, F. Varin, Physicochemical properties of neuromuscular blocking agents and their impact on the pharmacokinetic-pharmacodynamic relationship. Br J Anaesth 93, 241-248 (2004).

38. L. Bergamaschini, T. Santangelo, A. Faricciotti, N. Ciavarella, P. M. Mannucci, A. Agostoni, Study of complement-mediated anaphylaxis in humans. The role of IgG subclasses (IgG1 and/or IgG4) in the complement-activating capacity of immune complexes. J Immunol 156, 1256-1261 (1996).

39. F. Baert, M. Noman, S. Vermeire, G. Van Assche, D. H. G, A. Carbonez, P. Rutgeerts, Influence of immunogenicity on the long-term efficacy of infliximab in Crohn's disease. N Engl J Med 348, 601-608 (2003).

40. H. Subramanian, K. Gupta, H. Ali, Roles of Mas-related G protein-coupled receptor X2 on mast cell-mediated host defense, pseudoallergic drug reactions, and chronic inflammatory diseases. J Allergy Clin Immunol 138, 700-710 (2016).

41. B. D. McNeil, P. Pundir, S. Meeker, L. Han, B. J. Undem, M. Kulka, X. Dong, Identification of a mast-cell-specific receptor crucial for pseudo-allergic drug reactions. Nature 519, 237-241 (2015).

42. E. Florvaag, S. G. Johansson, The Pholcodine Case. Cough Medicines, IgE-Sensitization, and Anaphylaxis: A Devious Connection. World Allergy Organ J 5, 73-78 (2012).

43. L. K. James, S. J. Till, Potential Mechanisms for IgG4 Inhibition of Immediate Hypersensitivity Reactions. Curr Allergy Asthma Rep 16, 23 (2016).

44. H. Z. Movat, T. Uriuhara, N. S. Taichman, H. C. Rowsell, J. F. Mustard, The role of PMN-leucocyte lysosomes in tissue injury, inflammation and hypersensitivity. VI. The 
participation of the PMN-leucocyte and the blood platelet in systemic aggregate anaphylaxis. Immunology 14, 637-648 (1968).

45. B. Revenas, G. Smedegard, T. Saldeen, The pulmonary reaction in aggregate anaphylaxis in the monkey. Acta Chir Scand Suppl 499, 161-170 (1980).

46. G. Smedegard, B. Revenas, T. Saldeen, Aggregate anaphylaxis in the monkey: haematological and histological findings. Int Arch Allergy Appl Immunol 61, 117-124 (1980).

47. D. Spoerl, H. Nigolian, C. Czarnetzki, T. Harr, Reclassifying Anaphylaxis to Neuromuscular Blocking Agents Based on the Presumed Patho-Mechanism: IgEMediated, Pharmacological Adverse Reaction or "Innate Hypersensitivity"? Int J Mol Sci 18, (2017).

48. S. E. McKenzie, S. M. Taylor, P. Malladi, H. Yuhan, D. L. Cassel, P. Chien, E. Schwartz, A. D. Schreiber, S. Surrey, M. P. Reilly, The role of the human Fc receptor Fc gamma RIIA in the immune clearance of platelets: a transgenic mouse model. J Immunol 162, 4311-4318 (1999).

49. N. Tsuboi, K. Asano, M. Lauterbach, T. N. Mayadas, Human neutrophil Fcgamma receptors initiate and play specialized nonredundant roles in antibody-mediated inflammatory diseases. Immunity 28, 833-846 (2008).

50. K. Chen, H. Nishi, R. Travers, N. Tsuboi, K. Martinod, D. D. Wagner, R. Stan, K. Croce, T. N. Mayadas, Endocytosis of soluble immune complexes leads to their clearance by FcgammaRIIIB but induces neutrophil extracellular traps via FcgammaRIIA in vivo. Blood 120, 4421-4431 (2012).

51. B. Balbino, R. Sibilano, P. Starkl, T. Marichal, N. Gaudenzio, H. Karasuyama, P. Bruhns, M. Tsai, L. L. Reber, S. J. Galli, Pathways of immediate hypothermia and leukocyte infiltration in an adjuvant-free mouse model of anaphylaxis. J Allergy Clin Immunol 139, 584-596 e510 (2017).

52. R. Ahrens, H. Osterfeld, D. Wu, C. Y. Chen, M. Arumugam, K. Groschwitz, R. Strait, Y. H. Wang, F. D. Finkelman, S. P. Hogan, Intestinal mast cell levels control severity of oral antigen-induced anaphylaxis in mice. Am J Pathol 180, 1535-1546 (2012).

53. L. L. Reber, T. Marichal, K. Mukai, Y. Kita, S. M. Tokuoka, A. Roers, K. Hartmann, H. Karasuyama, K. C. Nadeau, M. Tsai, S. J. Galli, Selective ablation of mast cells or basophils reduces peanut-induced anaphylaxis in mice. J Allergy Clin Immunol 132, 881888 e811 (2013).

54. S. G. Brown, S. F. Stone, D. M. Fatovich, S. A. Burrows, A. Holdgate, A. Celenza, A. Coulson, L. Hartnett, Y. Nagree, C. Cotterell, G. K. Isbister, Anaphylaxis: clinical patterns, mediator release, and severity. J Allergy Clin Immunol 132, 1141-1149 e1145 (2013).

55. Y. Makabe-Kobayashi, Y. Hori, T. Adachi, S. Ishigaki-Suzuki, Y. Kikuchi, Y. Kagaya, K. Shirato, A. Nagy, A. Ujike, T. Takai, T. Watanabe, H. Ohtsu, The control effect of histamine on body temperature and respiratory function in IgE-dependent systemic anaphylaxis. J Allergy Clin Immunol 110, 298-303 (2002).

56. P. Gill, N. L. Jindal, A. Jagdis, P. Vadas, Platelets in the immune response: Revisiting platelet-activating factor in anaphylaxis. J Allergy Clin Immunol 135, 1424-1432 (2015).

57. J. M. Mencia-Huerta, R. A. Lewis, E. Razin, K. F. Austen, Antigen-initiated release of platelet-activating factor (PAF-acether) from mouse bone marrow-derived mast cells sensitized with monoclonal IgE. J Immunol 131, 2958-2964 (1983). 
58. L. B. Schwartz, Mediators of human mast cells and human mast cell subsets. Ann Allergy 58, 226-235 (1987).

59. J. Szebeni, F. M. Muggia, C. R. Alving, Complement activation by Cremophor EL as a possible contributor to hypersensitivity to paclitaxel: an in vitro study. J Natl Cancer Inst 90, 300-306 (1998).

60. M. R. Woolhiser, K. Brockow, D. D. Metcalfe, Activation of human mast cells by aggregated IgG through FcgammaRI: additive effects of C3a. Clin Immunol 110, 172-180 (2004).

61. M. Khodoun, R. Strait, T. Orekov, S. Hogan, H. Karasuyama, D. R. Herbert, J. Kohl, F. D. Finkelman, Peanuts can contribute to anaphylactic shock by activating complement. $J$ Allergy Clin Immunol 123, 342-351 (2009).

62. R. E. Lewis, Jr., J. M. Cruse, J. V. Richey, Effects of anesthesia and operation on the classical pathway of complement activation. Clin Immunol Immunopathol 23, 666-671 (1982).

63. M. Toussaint, D. J. Jackson, D. Swieboda, A. Guedan, T. D. Tsourouktsoglou, Y. M. Ching, C. Radermecker, H. Makrinioti, J. Aniscenko, M. R. Edwards, R. Solari, F. Farnir, V. Papayannopoulos, F. Bureau, T. Marichal, S. L. Johnston, Host DNA released by NETosis promotes rhinovirus-induced type-2 allergic asthma exacerbation. Nat Med 23, 681-691 (2017).

64. M. Saffarzadeh, K. T. Preissner, Fighting against the dark side of neutrophil extracellular traps in disease: manoeuvres for host protection. Curr Opin Hematol 20, 3-9 (2013).

65. S. Oehmcke, M. Morgelin, H. Herwald, Activation of the human contact system on neutrophil extracellular traps. J Innate Immun 1, 225-230 (2009).

66. A. Sala-Cunill, J. Bjorkqvist, R. Senter, M. Guilarte, V. Cardona, M. Labrador, K. F. Nickel, L. Butler, O. Luengo, P. Kumar, L. Labberton, A. Long, A. Di Gennaro, E. Kenne, A. Jamsa, T. Krieger, H. Schluter, T. Fuchs, S. Flohr, U. Hassiepen, F. Cumin, K. McCrae, C. Maas, E. Stavrou, T. Renne, Plasma contact system activation drives anaphylaxis in severe mast cell-mediated allergic reactions. J Allergy Clin Immunol 135, 1031-1043 e1036 (2015).

67. R. Munoz-Cano, M. Pascal, J. Bartra, C. Picado, A. Valero, D. K. Kim, S. Brooks, M. Ombrello, D. D. Metcalfe, J. Rivera, A. Olivera, Distinct transcriptome profiles differentiate nonsteroidal anti-inflammatory drug-dependent from nonsteroidal antiinflammatory drug-independent food-induced anaphylaxis. J Allergy Clin Immunol 137, 137-146 (2016).

68. C. Uermosi, F. Zabel, V. Manolova, M. Bauer, R. R. Beerli, G. Senti, T. M. Kundig, P. Saudan, M. F. Bachmann, IgG-mediated down-regulation of IgE bound to mast cells: a potential novel mechanism of allergen-specific desensitization. Allergy 69, 338-347 (2014).

69. D. MacGlashan, Jr., M. Mogowski, L. M. Lichtenstein, Studies of antigen binding on human basophils. II. Continued expression of antigen-specific IgE during antigeninduced desensitization. J Immunol 130, 2337-2342 (1983).

70. C. Kitzmuller, B. Nagl, S. Deifl, C. Walterskirchen, B. Jahn-Schmid, G. J. Zlabinger, B. Bohle, Human blood basophils do not act as antigen-presenting cells for the major birch pollen allergen Bet v 1. Allergy 67, 593-600 (2012). 
71. M. P. Hosking, R. L. Lennon, G. A. Gronert, Combined H1 and H2 receptor blockade attenuates the cardiovascular effects of high-dose atracurium for rapid sequence endotracheal intubation. Anesth Analg 67, 1089-1092 (1988).

72. S. G. Johansson, J. O. Hourihane, J. Bousquet, C. Bruijnzeel-Koomen, S. Dreborg, T. Haahtela, M. L. Kowalski, N. Mygind, J. Ring, P. van Cauwenberge, M. van HageHamsten, B. Wuthrich, E. n. t. force, A revised nomenclature for allergy. An EAACI position statement from the EAACI nomenclature task force. Allergy 56, 813-824 (2001).

73. J. Ring, K. Messmer, Incidence and severity of anaphylactoid reactions to colloid volume substitutes. Lancet 1, 466-469 (1977).

74. J. Sprung, T. N. Weingarten, L. B. Schwartz, Presence or absence of elevated acute total serum tryptase by itself is not a definitive marker for an allergic reaction. Anesthesiology 122, 713-714 (2015).

75. A. P. Uyttebroek, V. Sabato, C. H. Bridts, L. S. De Clerck, D. G. Ebo, Immunoglobulin E antibodies to atracurium: a new diagnostic tool? Clin Exp Allergy 45, 485-487 (2015).

76. D. G. Ebo, L. Venemalm, C. H. Bridts, F. Degerbeck, H. Hagberg, L. S. De Clerck, W. J. Stevens, Immunoglobulin E antibodies to rocuronium: a new diagnostic tool. Anesthesiology 107, 253-259 (2007).

77. S. G. Johansson, H. Oman, F. Degerbeck, J. Tunelli, E. Florvaag, A. Nopp, Anaphylaxis to atracurium - a non-QAI-dependent reaction? Acta Anaesthesiol Scand 56, 262-263 (2012).

78. V. Pravettoni, M. Piantanida, L. Primavesi, S. Forti, E. A. Pastorello, Basal plateletactivating factor acetylhydrolase: prognostic marker of severe Hymenoptera venom anaphylaxis. J Allergy Clin Immunol 133, 1218-1220 (2014).

79. G. Doge, R. Pohloudek-Fabini, D. Kottke, [Analysis and stability of suxamethonium chloride. 1. Detection and quantitative determination of the intact active agent with its degradation products]. Pharmazie 37, 708-711 (1982). 


\section{Acknowledgments:}

We are thankful to the team of the Pharmacoepidemiology Center of the Assistance PubliqueHôpitaux de Paris (AP-HP), and in particular Nessima Yelles, Karthiga Chandirakumaran and Imène Younes, at the Bichat hospital for their help with the NASA study logistics. From the Institut Pasteur, Paris, France, we thank Bruno Iannascoli for help with antibody purification, Frédéric Bonhomme for mass and NMR analyses of carboxylated rocuronium and suxamethonium, and Bruno Baron and Patrick England for microscale thermophoresis. We thank Vincent Guérineau (Institut de Chimie des Substances Naturelles, Gif-sur-Yvette, France) for the mass analyses of bioconjugates, Marine Parent, Sandy Peltier, Laurence Gaillanne and Celia Saint Louis-Augustin (Immunology Laboratory, Bichat Hospital, Paris) for help with sample management and immunology diagnostic tests. We thank Pr Marc Pallardy (Toxicology department, UFR de Pharmacie de l'Université Paris-Sud and INSERM UMR996) for fruitful discussions on NMBA allergy.

Funding: The NASA study was funded by AP-HP (Direction de la Recherche Clinique et de l'Innovation) through a «Contrat de Recherche Clinique 2011 », by INSERM (Institut National de la Santé et de la Recherche Médicale), by the French Ministry of health (Direction Générale de l'Offre de Soin, Paris, France) through a « Recherche Clinique translationnelle 2012» grant, by the European Research Council (ERC)-Seventh Framework Program (ERC-2013-CoG 616050 to PB), by the Institut Pasteur and the Institut National de la Santé et de la Recherche Médicale (INSERM). FJ is an employee of the Centre National de la Recherche Scientifique (CNRS). AGC benefited from a stipend provided by AP-HP, Paris, France and by the Institut Pasteur, Paris, France and from a grant provided by INSERM, SFAR (Société Francaise d'Anesthésie et de Reanimation) and SRLF (Société de Réanimation de Langue Française) through the "Bourse de 
Recherche du Comité d'interface INSERM-SFAR-SRLF 2012". CMG was supported partly by a stipend from the Pasteur-Paris University (PPU) International PhD program and by the Institut Carnot Pasteur Maladies Infectieuses. PB benefited from an additional support from AP-HP through a "Contral Local d'Interface 2014" and the "Département Hospitalo-Universitaire" (DHU) FIRE. The sponsor was the Direction de la Rercherche Clinique et de l'Innovation de l'AP-HP (France).

Author contributions: FJ, LdC, FT, MA, DL, SCM and PB conceived and designed the study. FJ, LdC, SCM and PB wrote the manuscript. FJ, LdC, VG, AGC performed and analyzed most of the in vitro and ex vivo studies, with help from CMG and PNR. CG and SB designed, produced and analyzed bioconjugates. FD and FT assisted with data analysis and statistical evaluation. CN and MTG assisted with clinical allergology evaluation. SCM and PB obtained grants to fund the study.

Competing interests: None of the authors declares a conflict of interest.

Data and materials availability: All data associated with this study are available in the main text or the supplementary materials.

\section{NASA study group}

Pierre Bruhns ${ }^{1,2}$, Friederike Jönsson ${ }^{1,2}$, Caitlin M. Gillis ${ }^{1,2}$, David A. Mancardi ${ }^{1,2}$, Pascale NicaiseRoland $^{3}$, Luc de Chaisemartin ${ }^{3,4}$, Sylvie Chollet-Martin ${ }^{3,4}$, Vanessa Granger ${ }^{3,4}$, Qianqian Zhu ${ }^{1,2,4}$, Dan Longrois ${ }^{3,5}$, Aurélie Gouel-Chéron ${ }^{1,2,5}$, Philippe Montravers ${ }^{5,19}$, Caroline Sauvan ${ }^{17}$, Fadia Dib $^{6}$, Sylvie Bay ${ }^{7,8}$, Christelle Ganneau ${ }^{7,8}$, Catherine Paugam-Burtz ${ }^{10}$, Skander Necib ${ }^{10}$, Hawa Keita-Meyer ${ }^{11}$, Valentina Faitot ${ }^{11}$, Alexandre Mebazaa ${ }^{12}$, Matthieu Le Dorze ${ }^{12}$, Bernard Cholley ${ }^{13}$, Jean Mantz ${ }^{13}$ (deceased), Olivier Langeron ${ }^{14}$, Sabrine Roche ${ }^{14}$, Laurent Jacob ${ }^{15}$, Benoit Plaud ${ }^{15}$, Carole Chahine ${ }^{15}$, Marc Fischler ${ }^{16}$, Marie-Thérèse Guinnepain ${ }^{18}$, Julie Bresson ${ }^{15}$, Michel Aubier $^{17,19}$, Catherine Neukirch ${ }^{17,19}$, Florence Tubach ${ }^{20}$, Antoine Mignon ${ }^{21}$. 
${ }^{1}$ Institut Pasteur, Department of Immunology, Unit of Antibodies in Therapy and Pathology, Paris, France; ${ }^{2}$ INSERM, U1222, Paris, France; ${ }^{3}$ HUPNVS, INSERM 1148, Université Paris-Diderot, Paris, France; ${ }^{4}$ Inflammation Chimiokines et Immunopathologie, INSERM UMRS996, Faculté de Pharmacie, Université Paris-Sud, Université Paris-Saclay, Châtenay-Malabry, France; ${ }^{5}$ APHP, Hôpital Bichat, Département d'Anesthésie-Réanimation, HUPNVS, Paris, France; ${ }^{6}$ APHP, Hôpital Bichat, Department of Epidemiology and Clinical Research, INSERM, Paris, France; ${ }^{7}$ Institut Pasteur, Département Biologie Structurale et Chimie, Unité de Chimie des Biomolécules, Paris, France; ${ }^{8} \mathrm{CNRS}$ UMR 3523, Paris, France; ${ }^{10}$ Département d'Anesthésie-Réanimation, Hôpital Beaujon, AP-HP, Clichy, France, and Université Paris Diderot, Paris, France; ${ }^{11}$ Service d'anesthésie, Hôpital Louis Mourier, AP-HP, Colombes, France and Université Paris Diderot, Sorbonne Paris Cité, EA Recherche Clinique coordonnée ville-hôpital, Méthodologies et Société (REMES), Paris, France; ${ }^{12}$ Département d'Anesthésie-Réanimation, Hôpital Lariboisière, AP-HP, Paris, France; ${ }^{13}$ Service d'Anesthésie-Réanimation, Hôpital Européen Georges Pompidou, AP-HP, Paris, France and Université Paris Descartes, Sorbonne Paris Cité, Paris, France; ${ }^{14}$ Department of Anesthesia and Critical Care, Hôpital Pitié Salpêtrière, AP-HP, Sorbonne Université, Paris, France and Infection and Epidemiology Department, Institut Pasteur Human Histopathology and Animal Models Unit, Paris, France; ${ }^{15}$ Département d'Anesthésie-Réanimation, Hôpital Saint Louis, APHP, Paris, France; ${ }^{16}$ Service d'Anesthésie, Hôpital Foch, Sureses, France; ${ }^{17}$ APHP, Hôpital Bichat, Service de Pneumologie A, HUPNVS, Paris, France; ${ }^{18}$ Hôpital Foch, Service de médecine interne, Suresnes, France; ${ }^{19}$ INSERM 1152, DHU FIRE, Labex Inflamex, Université Paris Diderot Paris 7, Paris, France; ${ }^{20}$ Sorbonne Université, AP-HP, Hôpital Pitié-Salpêtrière, Département Biostatistique Santé Publique et Information Médicale, Unité de Recherche Clinique PSL-CFX, Centre de Pharmacoépidémiologie (Cephepi), INSERM, UMR 1123, CIC-1421, Paris; ${ }^{21}$ Département d'anesthésie-réanimation, Hôpital Cochin, AP-HP, Paris, France. 
Table1. Characteristics of the patients

\begin{tabular}{|c|c|c|c|}
\hline Variable & $\begin{array}{c}\text { Cases } \\
(\mathrm{n}=86)\end{array}$ & $\begin{array}{c}\text { Controls } \\
(n=86)\end{array}$ & $\mathrm{p}$ \\
\hline Female gender & $62 \%$ & $62 \%$ & $1 *$ \\
\hline Age (years) & $57[40 ; 66]$ & $58[42 ; 66]$ & 0.66 \\
\hline Previous general anaesthesia & $84 \%$ & $87 \%$ & $0.66 *$ \\
\hline Medication (ACEI/ARA/BB/CI) & $38 \%$ & $29 \%$ & $<0.0001^{*}$ \\
\hline \multicolumn{4}{|l|}{ History of allergy } \\
\hline Drugs & $13 \%$ & $13 \%$ & $1 *$ \\
\hline Latex & $2 \%$ & $8 \%$ & $0.17 *$ \\
\hline Food & $7 \%$ & $0 \%$ & $0.03^{*}$ \\
\hline Hymenoptera venom & $3 \%$ & $0 \%$ & $0.09 *$ \\
\hline Pollen/Moth/Animals/Mold & $15 \%$ & $13 \%$ & $0.83 *$ \\
\hline Asthma & $12 \%$ & $5 \%$ & $0.16^{*}$ \\
\hline Atopy & $21 \%$ & $19 \%$ & $0.85 *$ \\
\hline \multicolumn{4}{|l|}{ Type of surgery } \\
\hline Cardio-thoracic, vascular & $20 \%$ & $20 \%$ & $1 *$ \\
\hline Maxillo-facial & $8 \%$ & $8 \%$ & $1 *$ \\
\hline Orthopedic Neurosurgery & $20 \%$ & $20 \%$ & $1 *$ \\
\hline Visceral, Urologic, Gynecologic & $52 \%$ & $52 \%$ & $1 *$ \\
\hline Scheduled surgery & $92 \%$ & $98 \%$ & $0.17^{*}$ \\
\hline Surgery with a context of infection & $2.3 \%$ & $2.3 \%$ & $0.87 *$ \\
\hline NMBA used during surgery & & & $0.84^{*}$ \\
\hline Suxamethonium & $56 \%$ & $56 \%$ & $1 *$ \\
\hline Atracurium & $51 \%$ & $51 \%$ & $1 *$ \\
\hline Rocuronium & $3 \%$ & $3 \%$ & $1 *$ \\
\hline
\end{tabular}

Values are expressed as percentages or as median $\left[25^{\text {th }}-75^{\text {th }}\right.$ percentile $]$.

$\checkmark$ Student test. * Exact Fisher test. ACEI: Angiotensin-Converting-Enzyme Inhibitor. ARA:

Angiotensin II Receptor Antagonist. BB: Beta-blocker. CI: Calcium channel inhibitor. NMBA: Neuro-muscular Blocking Agent. 
Table 2. Clinical signs and therapeutic interventions during acute hypersensitivity reactions, according to severity grade.

\begin{tabular}{|c|c|c|c|}
\hline Clinical/Haemodynamic signs & Severe & Mild & $\mathbf{P}$ \\
\hline Erythema, \% & 65 & 79 & $0.2 *$ \\
\hline Tachycardia, \% & 58 & 44 & $0.3 *$ \\
\hline Maximum HR, min $^{-1}$ & $130[125 ; 1$ & $127[111 ; 136]$ & $0.3 \diamond$ \\
\hline Bradycardia, \% & 26 & 7 & $0.04 *$ \\
\hline Minimum HR, min $^{-1}$ & $42[40 ; 49]$ & $52[51 ; 54]$ & $0.1 \diamond$ \\
\hline Arrhythmia, \% & 23 & 2 & $0.007^{*}$ \\
\hline Arterial hypotension, \% & 100 & 63 & $<0.0001^{*}$ \\
\hline Minimum SAP value, $\mathrm{mmHg}$ & $50[43 ; 60]$ & $65[58 ; 73]$ & $0.01 \diamond$ \\
\hline Bronchospasm, \% & 37 & 28 & $0.5 *$ \\
\hline Hypoxemia, \% & 49 & 7 & $<0.0001^{*}$ \\
\hline Minimum $\mathrm{SpO}_{2}, \%$ & $82[82 ; 88]$ & $91[90 ; 91]$ & $0.1 \diamond$ \\
\hline Hypocapnia, \% & 63 & 14 & $<0.0001 *$ \\
\hline Minimum etCo $2, \mathrm{mmHg}$ & $18[13 ; 21]$ & $26[24 ; 29]$ & $0.002 \diamond$ \\
\hline Cardiac arrest, $\%$ & 23 & 0 & $0.001 *$ \\
\hline \multicolumn{4}{|l|}{ Delay of resuscitation } \\
\hline Delay between anaesthesia induction and first signs of the reaction (min) & $5[5 ; 16]$ & $5.5[5 ; 10]$ & 0.60 \\
\hline Delay between first signs of the reaction and treatment initiation (min) & $1[0 ; 2]$ & $0[0 ; 0.75]$ & 0.0080 \\
\hline \multicolumn{4}{|l|}{ Therapeutic interventions } \\
\hline Epinephrine IV alone, $\%$ & 35 & 0 & $<0.0001^{*}$ \\
\hline Cumulative doses of epinephrine (mg) & $2.5[1 ; 6.9]$ & NA & NA \\
\hline Norepinephrine IV alone, $\%$ & 5 & 0 & $0.5 *$ \\
\hline Cumulative doses of norepinephrine IV (mg) & $1.75[1.62$ & NA & NA \\
\hline Epinephrine IV and Norepinephrine IV, \% & 12 & 0 & $0.06 *$ \\
\hline Cumulative doses of epinephrine IV (mg) & $5[2 ; 5.4]$ & NA & NA \\
\hline Ephedrine and/or phenylephrine IV alone, \% & 0 & 44 & $<0.0001^{*}$ \\
\hline Ephedrine and/or phenylephrine IV, then epinephrine and/or norepinephrine & 49 & 2 & $<0.0001 *$ \\
\hline Cumulative doses of epinephrine IV (mg) & $0.6[0.3 ; 4.1$ & 0.1 & NA \\
\hline Atropine IV, \% & 12 & 5 & $0.4^{*}$ \\
\hline Cumulative doses of atropine IV (mg) & $1[1 ; 1]$ & $1[1 ; 1]$ & NA \\
\hline Beta2-adrenergic agonist IV/inhaled, \% & 14 & 12 & $1^{*}$ \\
\hline Glucocorticoids, \% & 23 & 23 & $1^{*}$ \\
\hline Histamine receptor antagonists, $\%$ & 0 & 2 & $1^{*}$ \\
\hline Fluid resuscitation with crystalloids, \% & 70 & 42 & $0.02 *$ \\
\hline Cumulative volume of crystalloids (1) & $1[1 ; 2]$ & $0.87[0.5 ; 1.37]$ & 0.030 \\
\hline Fluid resuscitation with colloids, \% & 83 & 9 & $0.008 *$ \\
\hline Cumulative volume of colloids (l) & $0.5[0.5 ; 1]$ & $0.65[0.5 ; 0.85]$ & $0.8 \diamond$ \\
\hline \multicolumn{4}{|l|}{ Evolution } \\
\hline Surgery cancelled, $\%$ & 81 & 19 & $<0.0001^{*}$ \\
\hline Admission to ICU, \% & 76 & 26 & $<0.0001^{*}$ \\
\hline
\end{tabular}

Values are expressed as percentages or as median $\left[25^{\text {th }}-75^{\text {th }}\right.$ percentile $]$ when appropriate. The numbers of observations and missing values varied according to the numeric value analysed: maximum HR (43/17), minimum HR (14/6), minimum PAS (70/21), minimum $\mathrm{SpO}_{2}(24 / 9)$, minimum etCO $2(33 / 7)$.

etCO : end-tidal $\mathrm{CO}_{2}$. HR: Heat Rate. ICU: Intensive Care Unit. IV: Intravenous. NA: Nonavailable. ND: Not-done. SAP: Systolic arterial Pressure. $\mathrm{SpO}_{2}$ : Photoplethysmographic oxygen saturation. $\diamond$ Mann \& Whitney test. * Exact Fisher test. 


\section{FIGURES}

\section{Figure 1}

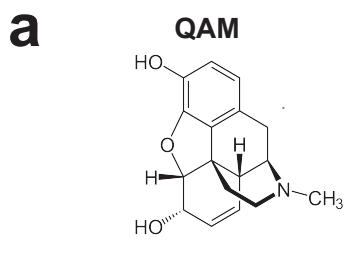

b Suxamethonium<smiles>C[N+](C)(C)CCOC(=O)CCC(=O)OCC[N+](C)(C)C</smiles>

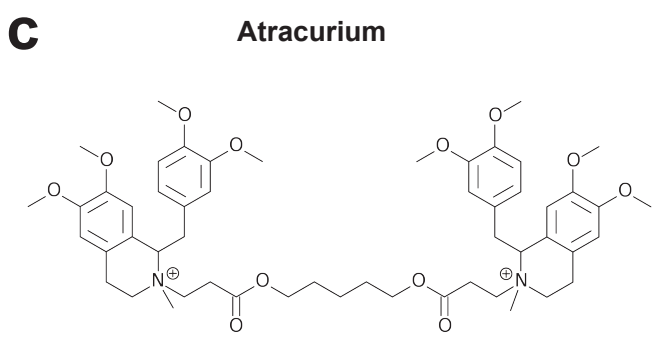

d Rocuronium
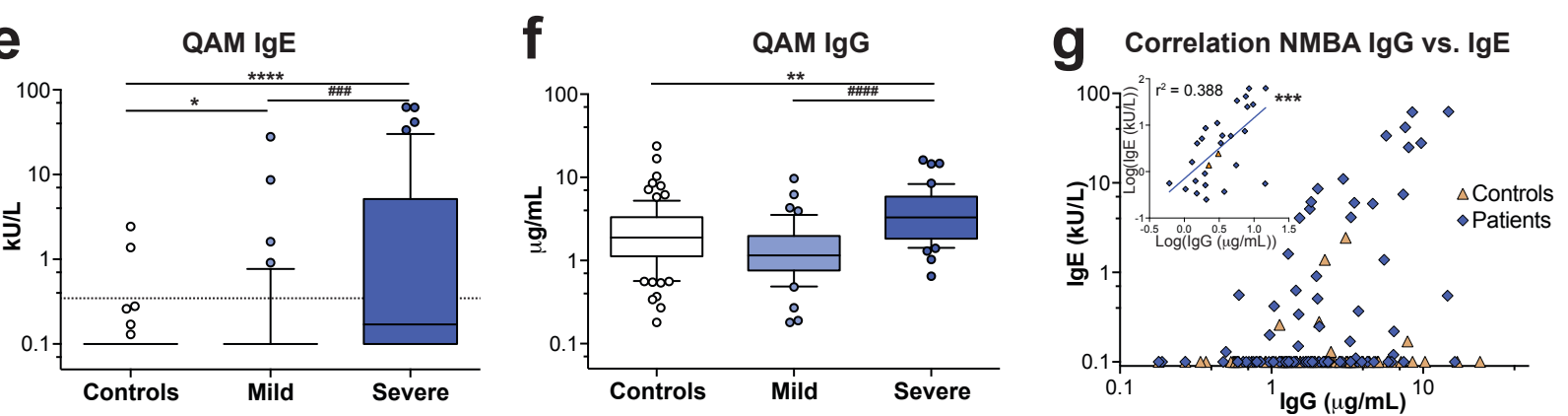

Figure 1: Anti-NMBA specific antibodies concentrations are elevated in severe AHR

(a-d) Schematic representation of (a) morphine (QAM), (b) suxamethonium, (c) atracurium and (c) rocuronium). (e,f) Measurements of (e) $\operatorname{IgE}$ and (f) $\operatorname{IgG}$ against quaternary ammonium morphine antigen (QAM) in patients presenting with mild AHR $(n=43)$, severe AHR $(n=43)$ and matched controls $(\mathrm{n}=86)$. Wilcoxon signed rank test: $* * * * \mathrm{P}<0.0001, * * \mathrm{P}<0.01, * \mathrm{P}<0.05$. MannWhitney test: \#\#\#\#P<0.0001, \#\#\#P<0.001. (d,e) Results are represented as boxplots; whiskers indicate the $10^{\text {th }}$ and $90^{\text {th }}$ percentiles. (g) Plotting of individual data of anti-QAM IgE and $\operatorname{IgG}$ concentrations for controls (orange triangles) and patients (blue diamonds). Inset: correlation plot including only patients and controls with anti-QAM $\operatorname{IgE}>0.3 \mathrm{kU} / \mathrm{L}$. Spearman-correlation: $* * * \mathrm{P}<0.001$ 


\section{Figure 2}
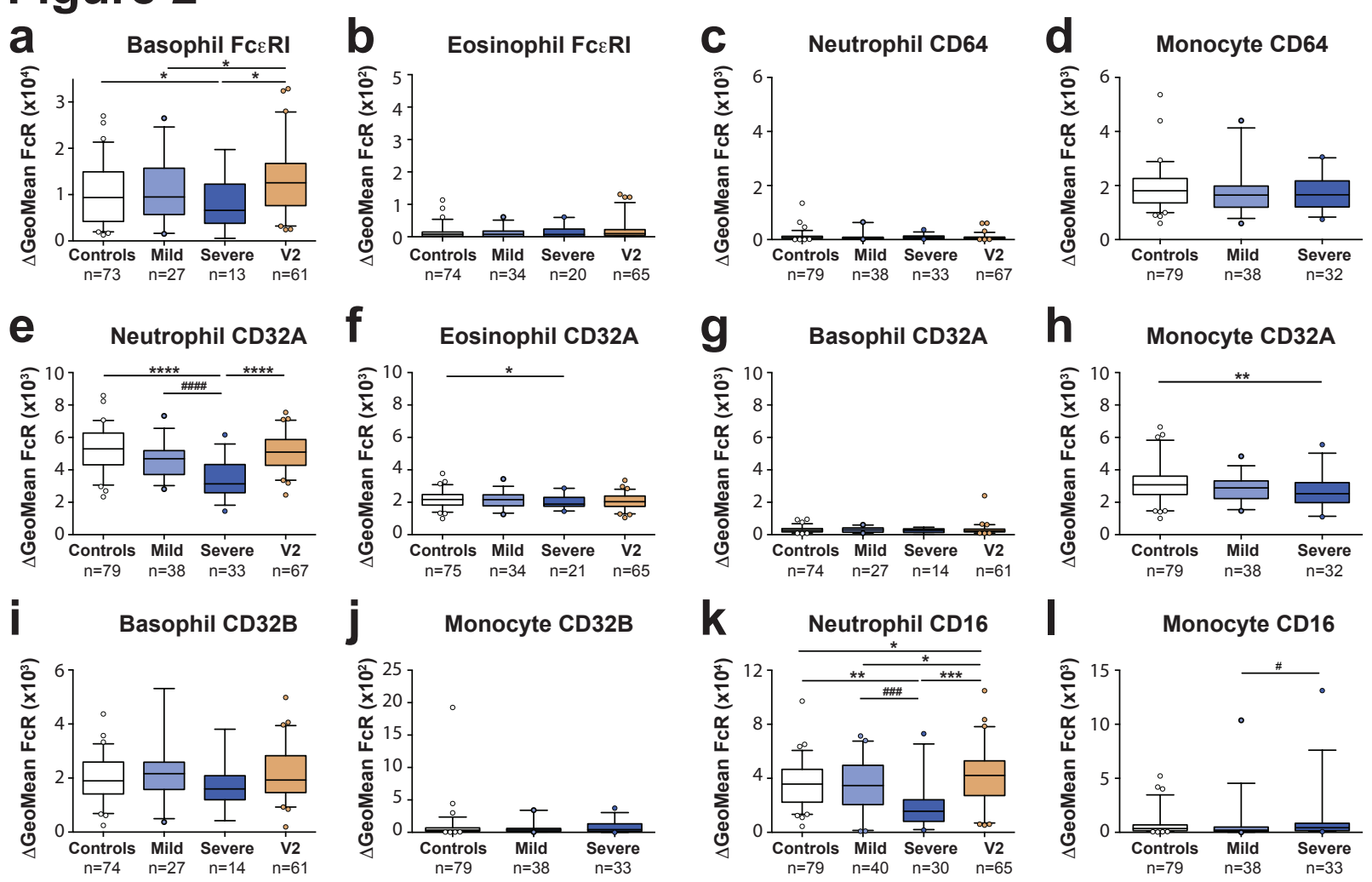

Figure 2 : Modulation of IgE and IgG receptor expression on myeloid cells during AHR

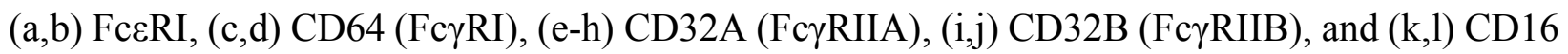
(FcyRIII) expression on circulating basophils (a,g,i), eosinophils (b,f), neutrophils (c,e,k) and monocytes $(\mathrm{d}, \mathrm{h}, \mathrm{j}, \mathrm{l})$ in the blood from patients 30 minutes after onset of AHR, during the followup visit (V2) or from matched controls. Values represent the delta geometric mean ( $\Delta$ GeoMean) between specific staining and corresponding isotype or fluorescence-minus-one control. Wilcoxon signed rank test: $* * * * \mathrm{P}<0.0001, * * * \mathrm{P}<0.001, * * \mathrm{P}<0.01, * \mathrm{P}<0.05$. Mann-Whitney test: $\# \# \# \mathrm{P}<0.0001, \# \# \mathrm{P}<0.01, \# \mathrm{P}<0.1$. All boxplots whiskers represent $5^{\text {th }}$ and $95^{\text {th }}$ percentiles. 

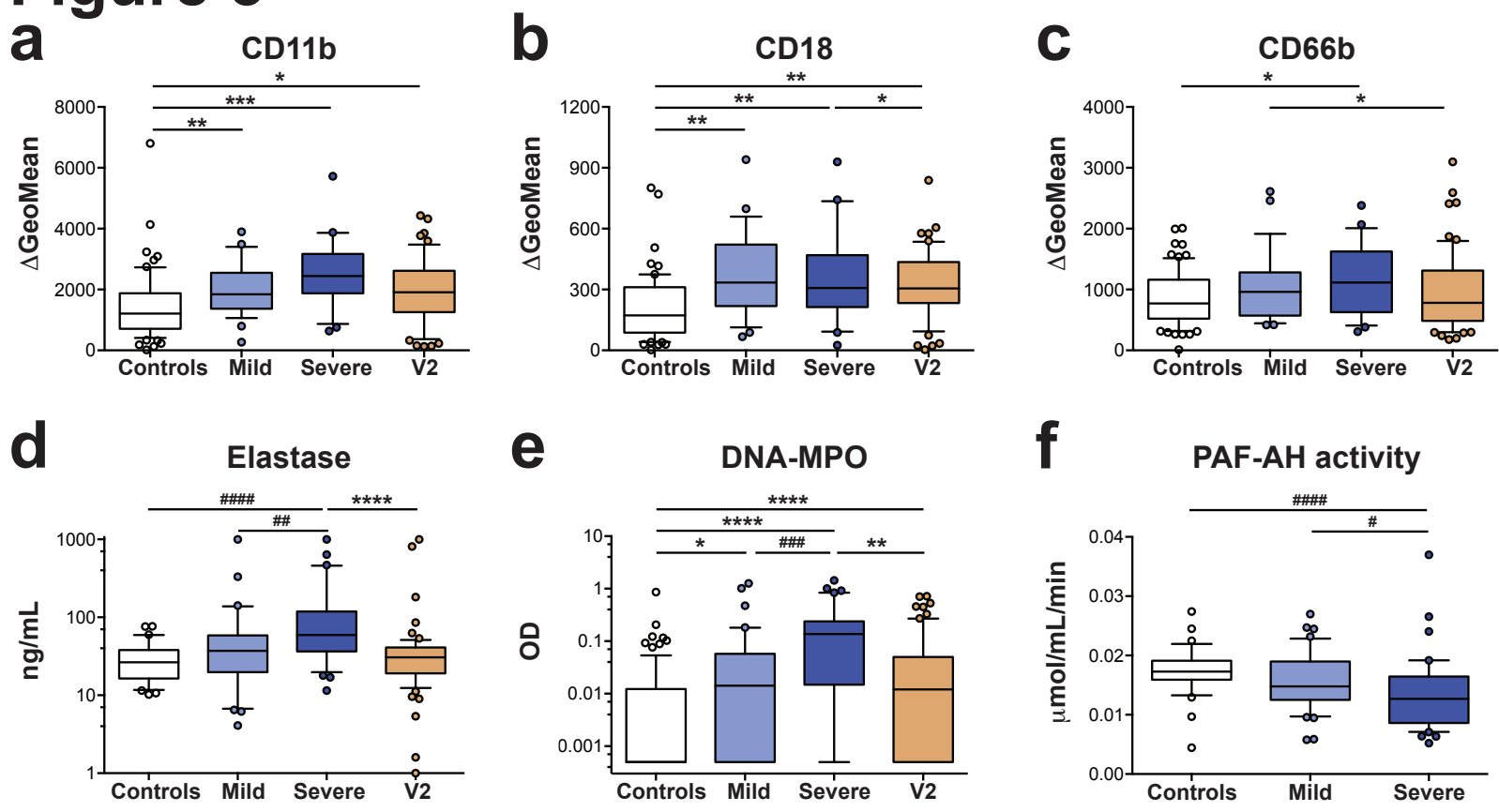

Figure 3: Circulating neutrophils are activated during AHR.

(a-c) Surface expression on circulating neutrophils of activation markers (a) CD11b, (b) CD18 and (c) CD66b expressed as geometric mean of fluorescence intensity after subtraction of isotype control. (d) Neutrophil elastase in the plasma of patients 30 minutes after AHR occurrence in mild $(n=37)$ or severe $(n=32)$ AHR patients, at their follow-up visit (V2, $n=69)$ or in healthy controls $(n=30)$. (e) Circulating NETs measured as DNA-MPO complexes in the serum of patients 30 minutes after AHR occurrence in mild $(n=43)$ or severe $(n=43)$ AHR patients, at their follow-up visit (V2, $n=86)$ or in matched controls $(n=86)$. (f) Activity of PAF-AH in the plasma of patients 30 minutes after AHR occurrence in mild $(n=42)$ or severe $(n=42)$ AHR patients, or of healthy controls $(\mathrm{n}=33)$. Wilcoxon signed rank test: $* * * * \mathrm{P}<0.0001, * * * \mathrm{P}<0.001, * * \mathrm{P}<0.01, * \mathrm{P}<0.05$. Mann-Whitney test: \#\#\#\#P $<0.0001, \# \# \# \mathrm{P}<0.001, \# \# \mathrm{P}<0.01$. All boxplots whiskers represent $10^{\text {th }}$ and $90^{\text {th }}$ percentiles. 


\section{Figure 4}
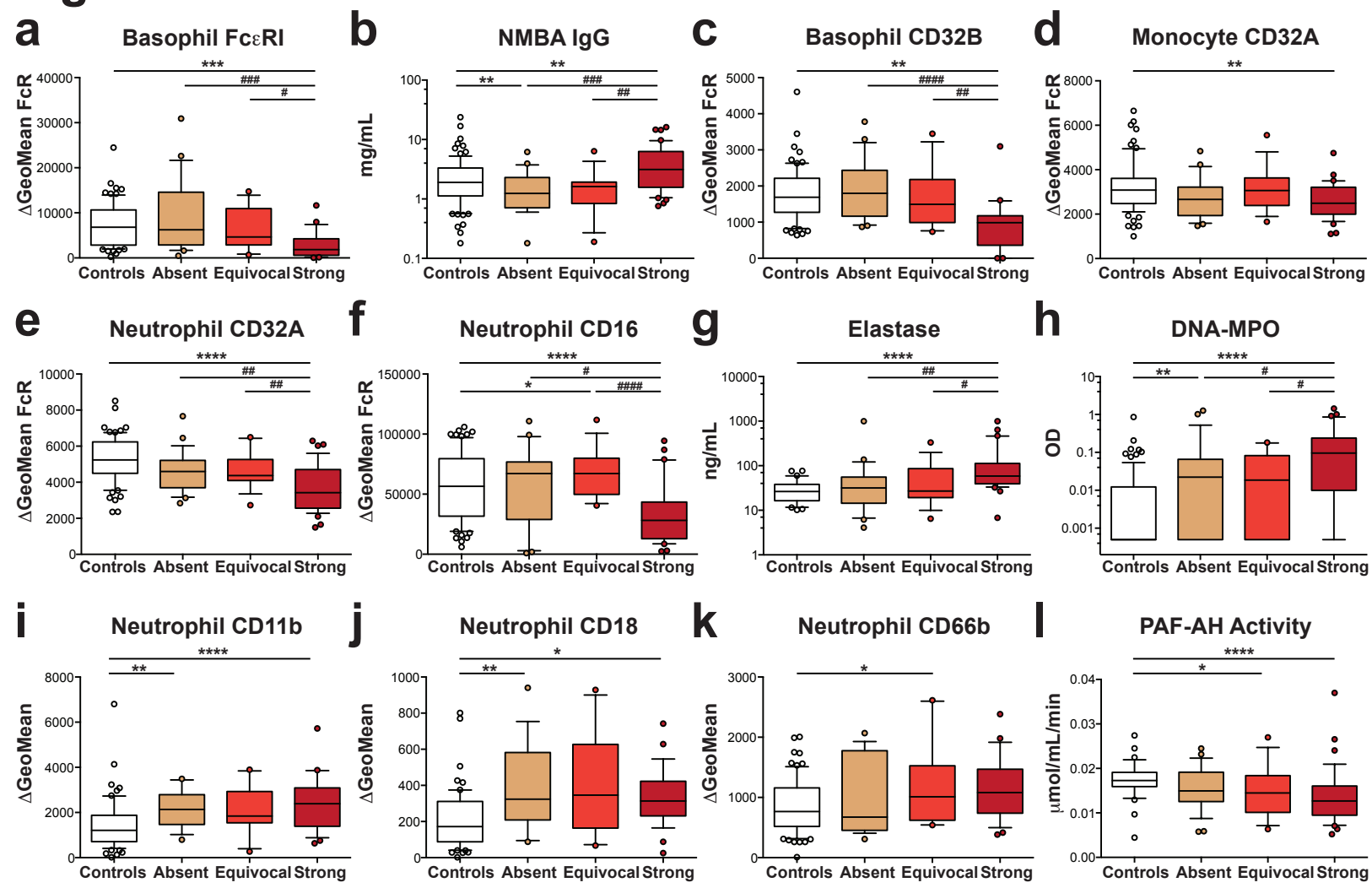

Evidence for IgE-dependent pathway

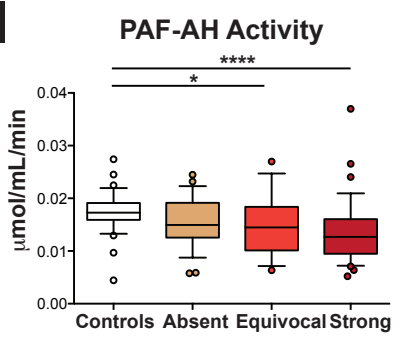

Figure 4: Evidence of an IgG-neutrophil-PAF pathway in the presence or absence of IgEmediated anaphylaxis markers

Evidence for IgE-dependent anaphylaxis was classified as "absent" $(\mathrm{n}=27)$, "equivocal” ( $\mathrm{n}=19)$ or "strong" $(n=40)$ for each patient of the NASA cohort. Data from Figures 1-3 were reanalyzed based on these criteria, and (a) FceRI expression on basophils, (b) anti-NMBA IgG, or (c) CD32B expression on basophils, (d) CD32A expression on monocytes, (e) CD32A or (f) CD16 expression on neutrophils, circulating (g) neutrophil elastase or (h) NETs (DNA-MPO complexes), (i) CD11b, (j) CD18, (k) CD66b expression on neutrophils and (i) plasma PAF-AH activity were compared between controls and patients with "absent", "equivocal" or "strong" evidence for IgE-dependent anaphylaxis. Wilcoxon signed rank test: $* * * * \mathrm{P}<0.0001, * * * \mathrm{P}<0.001, * * \mathrm{P}<0.01, * \mathrm{P}<0.05$. Mann-

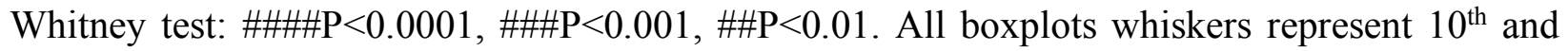
$90^{\text {th }}$ percentiles. 
Figure 5

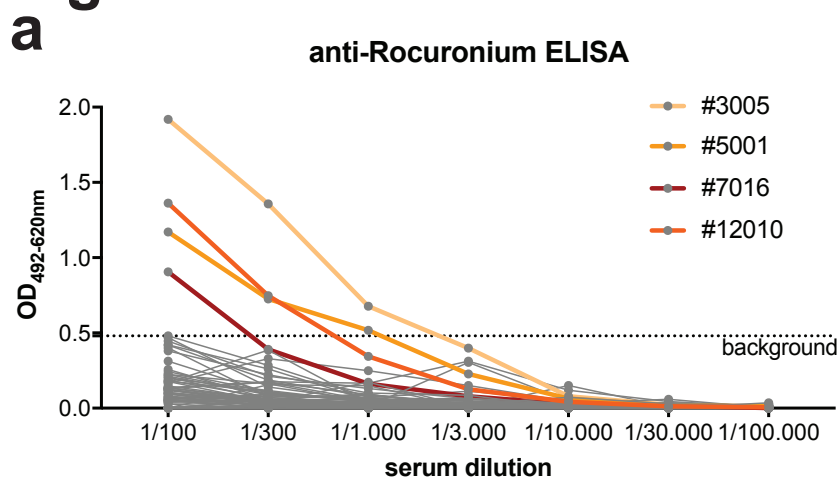

C IC binding to Fc $\gamma$ RIIIA

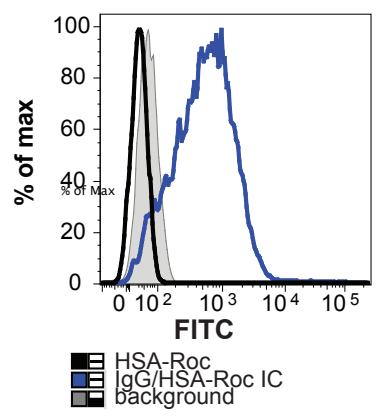

b

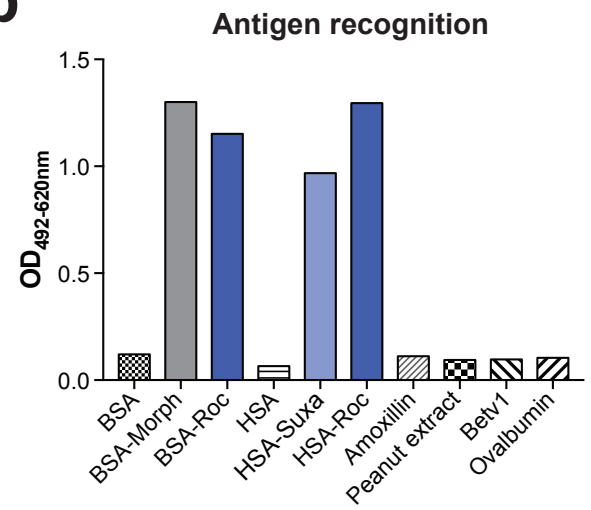

e

Cell-free DNA

Figure 5: [NMBA - anti-NMBA IgG] complexes activate neutrophils ex vivo

(a) Anti-rocuronium ELISA revealing 4 patients with high rocuronium-specific IgG antibody (colored lines) in the cohort (all other patients are indicated by grey lines). (b) Specificity of purified anti-rocuronium IgG measured by ELISA against indicated protein antigens and their morphine- (Morph), suxamethonium (Suxa)-, rocuronium (Roc)-derivatives or against common allergens: amoxicillin, peanut extract, Bet v 1 (the major birch pollen antigen, Betula verrucosa) and ovalbumin. One of two independent experiments (c) Flow cytometric analysis of the binding of [anti-rocuronium IgG + rocuronium-HSA] immune complexes to cell transfectants expressing human CD16A/FcyRIIIA variant V176 (blue line), compared to rocuronium-HSA alone (black line), and unstained cells (grey shaded histogram), one of three independent experiments. $(\mathrm{d}, \mathrm{e})$ Fluorescent-based measurement of (d) ROS or (e) cell-free DNA (NETs) released by purified neutrophils from healthy donors $(n=4)$, either left untreated (media), or incubated with control ICs (OVA IC), rocuronium-HSA (HSA-Roc) or [anti-rocuronium IgG + rocuronium-HSA] complexes (Roc IC). Error bars represent standard deviation. $* \mathrm{P}<0.01$, Mann-Whitney test. 